\title{
Biaryl synthesis with control of axial chirality
}

\section{Timothy W. Wallace*}

\section{Received 14th June 2006}

First published as an Advance Article on the web 1st August 2006

DOI: $10.1039 / \mathrm{b} 608470 \mathrm{~m}$

Biaryls have been a persistent focus of interest for chemists since it was recognised, more than 80 years ago, that they can manifest the axial chirality that is inherent in structures consisting of intersecting dissymmetric planes. In recent decades their importance has risen steeply as this structural motif proved spectacularly successful in catalytic synthetic roles and was found to be significant in the context of biological activity. As a consequence, synthetic methods which allowed the construction of biaryls with axial stereocontrol have become highly desirable, and this article traces the development of non-resolution approaches to biaryls with a chosen axial configuration.

\section{Introduction}

Axially enantiopure biaryls are highly prized molecules. Preeminent are the 2,2'-disubstituted 1,1'-binaphthyls typified by $\mathbf{1}$ and $\mathbf{2}$, whose properties have been widely exploited in synthetic, materials and supramolecular chemistry. ${ }^{1}$ The key component of such molecules, a conformationally restrained stereogenic axis, can also be biologically important, there being a number of compounds whose biological activity is dependent on such a feature. In some of these the axis is the sole stereogenic element, as in the case of $(R)-(-)$-deacetamidocolchicine $\mathbf{3}$ which, unlike its mirror-image (atropisomeric) $(S)$-form, binds strongly to the cellular protein tubulin. ${ }^{2}$ Alternatively, the axis may be one of

School of Chemistry, The University of Manchester, Oxford Road, Manchester, UK M13 9PL.E-mail: tim.wallace@manchester.ac.uk; Fax: +44 (0) 1612754598

Tim Wallace obtained a degree in chemistry in 1971 at Imperial College, London, where remained to carry out research with Peter Sammes which led to the award of a PhD in 1974. After postdoctoral research with Charles Jefford (Geneva) and Sir John Cornforth (Sussex), in 1980 he was appointed to a lectureship at Salford University, becoming a senior lecturer in 1987. In 2001 he moved to UMIST, now The University of Manchester, where he is currently a senior lecturer in the School of Chemistry.

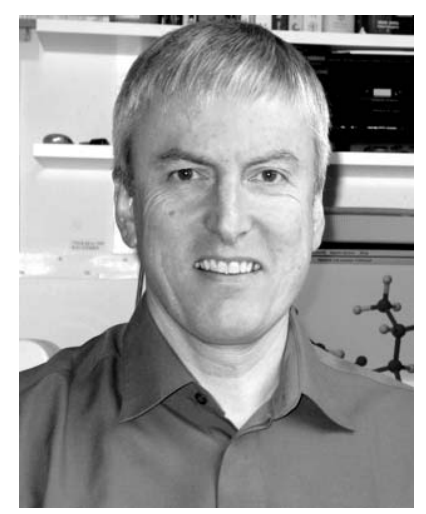

Tim Wallace a series of stereogenic elements whose interplay engenders a complex conformational equilibrium within a molecule, as with the glycopeptide antibiotic vancomycin $\mathbf{4}$ and related structures. ${ }^{3,4}$<smiles>c1ccc(-c2ccccc2-c2c(-c3ccccc3)ccc3ccccc23)cc1</smiles>

1 BINAP<smiles>Oc1ccc2ccccc2c1-c1c(O)ccc2ccccc12</smiles>

2 BINOL<smiles>COc1cc2c(c(OC)c1OC)-c1ccc(OC)c(=O)cc1CCC2</smiles>

3

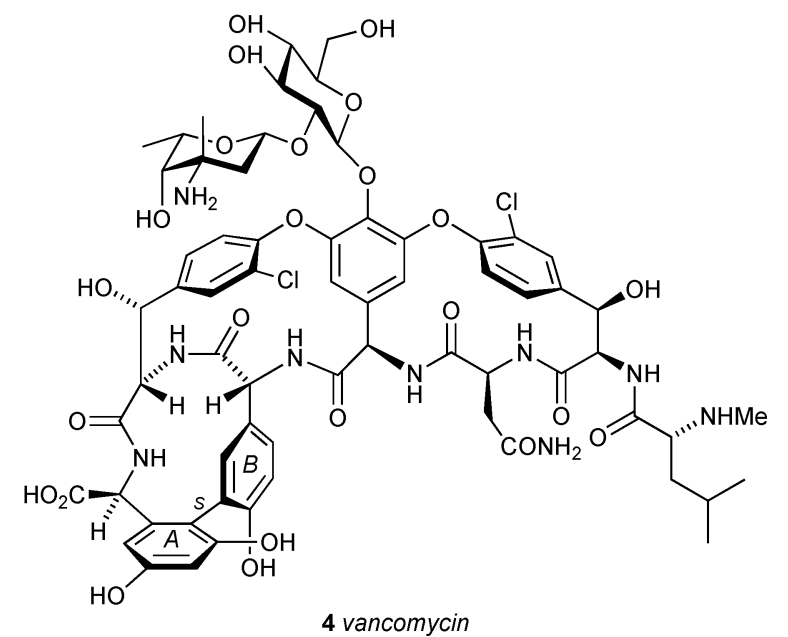

The presence of a stereogenic axis within a target molecule offers the same initial prospect as a stereogenic centre, namely the potential doubling of the stereoisomer count for each uncontrolled installation. In the context of central chirality, recent decades have witnessed the development of many reliable methods for stereocontrolled synthesis. Meanwhile the problem of axial stereocontrol has offered some different challenges, one being the absence of an axial equivalent of the 'chiral pool' from which prefabricated stereogenic units might be redeployed for synthetic purposes. Consequentially, classical resolution has remained an important source of enantiopure biaryls and techniques for controlling axial stereochemistry during their construction have emerged 
more slowly. Nevertheless, anyone intent on axially-controlled (atroposelective) biaryl synthesis can now select from various protocols, these being the fruits of much effort and ingenuity over the last 25 years. The objective of this article is to examine some of the developments over this period, and the coverage is illustrative and selective rather than comprehensive. For the reader seeking the latter, the excellent review by Bringmann et al. ${ }^{5}$ is recommended.

\section{Non-catalytic intermolecular aryl-aryl coupling reactions}

In 1980 the long-established route to symmetrical biaryls via the copper-mediated coupling of haloarenes (the Ullmann reaction ${ }^{6}$ ) was modified by Miyano et al., who incorporated central chirality into 1-bromo-2-naphthoates using chiral alcohols such as (-)-menthol (Scheme 1). ${ }^{7}$ The diastereoselectivity that accompanied the conversion of $\mathbf{5}$ into the binaphthyl $\mathbf{6}$ set an important precedent which was later exploited by Meyers and coworkers using oxazoline moieties derived from chiral amino alcohols as masked carboxylic acid groups. High selectivity proved possible with this system, as illustrated by the conversion of 7 into 9 (Scheme 2$)^{8}$ which can be directly compared to the result in Scheme 1. The sense of induction leading to $\mathbf{8}$ was ascribed to the intermediacy of a copper-containing complex, represented as $\mathbf{1 0}$, that is sterically favoured over the corresponding $(\mathrm{a} R)-\mathbf{8}$ precursor.

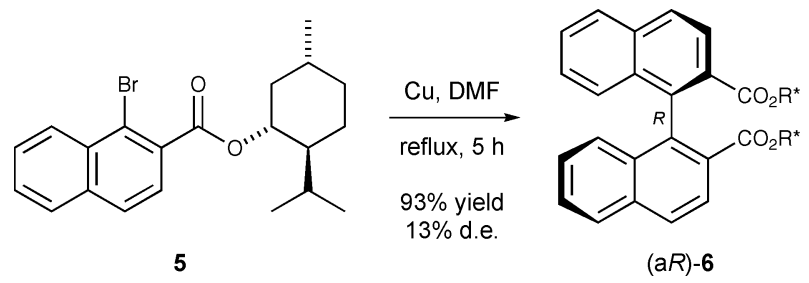

Scheme 1 The first asymmetric Ullmann reaction. ${ }^{7}$<smiles>Brc1c(C2=N[C@@H](Br)CO2)ccc2ccccc12</smiles>

$\underset{\text { reflux } 24 \mathrm{~h}}{\stackrel{\text { Cu, pyridine }}{\longrightarrow}}$

$94 \%$ d.e.

(S)-7
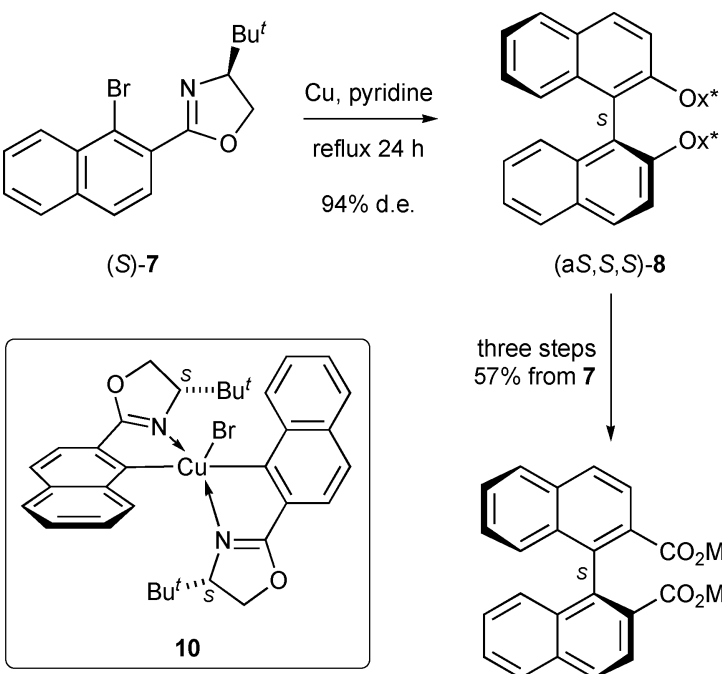

$(a S, S, S)-8$

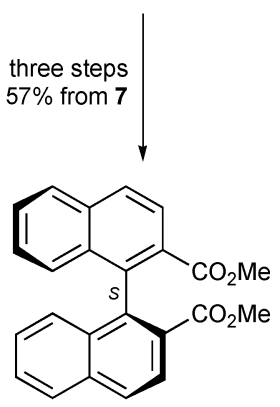

(aS)-9

Scheme 2 Nelson and Meyers' asymmetric Ullmann reaction. ${ }^{8}$

In applying the oxazoline-based Ullmann reaction to the preparation of $(S) \mathbf{- 1 4}$, required for the synthesis of ellagitannins,
Nelson and Meyers observed high diastereoselectivity in the homocoupling of the $(S)$-valinol derived oxazoline $12,{ }^{9}$ but discovered that the ratio of the two products $(\mathrm{a} S)-\mathbf{1 3}$ and $(\mathrm{a} R)$ 13 only reached the maximum value $(93: 7)$ after a prolonged reaction time (Scheme 3). ${ }^{10,11}$ After further experimentation it was concluded that a thermodynamically-controlled resolution was contributing to the observed selectivity, and that copper was an essential component of the process. A model involving the copperassisted thermal equilibration of the atropisomeric forms of $\mathbf{1 3}$ was proposed (Scheme 3, inset).<smiles>CC[C@H]1COC(c2cc(OC)c(OC)c(OC)c2Br)=N1</smiles>

(S)-12<smiles>COc1cc(C(=O)O)c(Br)c(OC)c1OC</smiles>

11

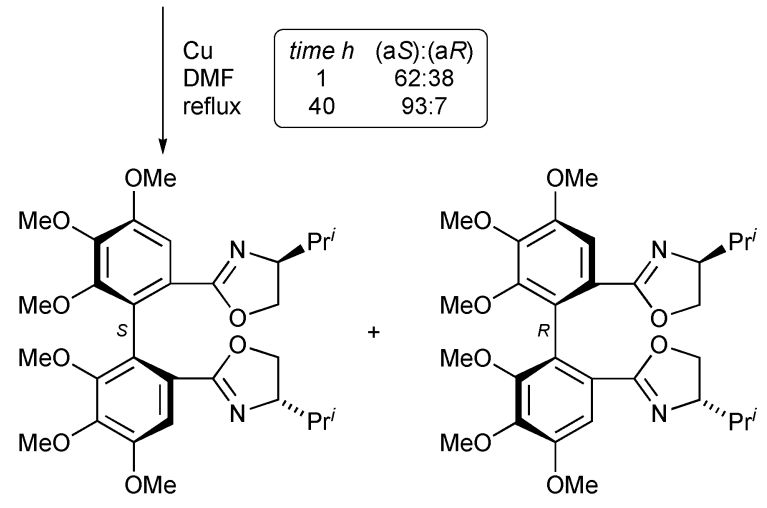

$(\mathrm{aS}, \mathrm{S}, \mathrm{S})-13$<smiles>COc1cc(C(=O)O)c(-c2c(C(=O)O)cc(OC)c(OC)c2OC)c(OC)c1OC</smiles>

$(a R, S, S)-13$

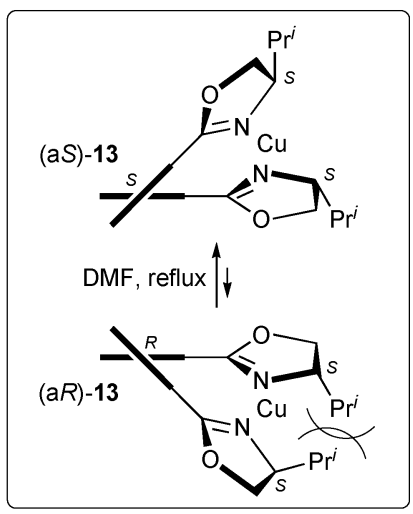

Scheme 3 Synthesis of the ellagitannin precursor $(S)-14 .^{9-11}$

In a more recent example of homocoupling followed by thermodynamic equilibration, Kumadaki et al. ${ }^{12}$ prepared a series of 1,1'biaryl-2,2-dialkanols bearing perfluoroalkylated side-chains with central chirality in the benzylic positions. In a typical sequence (Scheme 4), the nickel-mediated homocoupling of the MOMprotected bromoarene $(R)$-15 gave the diastereoisomeric biaryls $(\mathrm{a} R)-16$ and $(\mathrm{a} S)-16$ in respective yields of 69 and $11 \%$. Removal of the protecting groups followed by heating at $110{ }^{\circ} \mathrm{C}$ resulted in equilibration with convergence to the diol $(\mathrm{a} R)-\mathbf{1 7}$. The influence of ortho-benzylic central chirality on the formation and stability of unsymmetrical biaryl axes is a recurrent theme in their synthesis. 
<smiles>CO[C@H](c1ccccc1Br)C(F)(F)C(F)(F)F</smiles>

$(R)-15$<smiles>CO[C@H](c1ccccc1-c1ccccc1[C@@H](OC)C(F)(F)C(F)(F)F)C(F)(F)C(F)(F)F</smiles>

$(\mathrm{a} R, R, R)-16$ 69\%

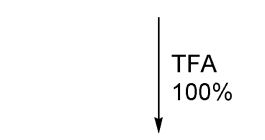<smiles>CC(C)(C)OC(=O)C(F)(F)C(F)(F)C(F)(F)F</smiles>

$(\mathrm{a} R, R, R)-17$
$\mathrm{Ni}(\mathrm{COD})_{2}$

$\mathrm{DMF}, 60^{\circ} \mathrm{C}$

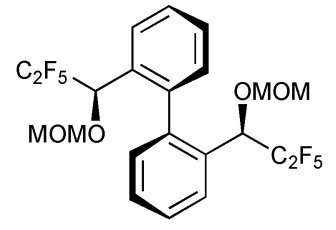

(aS,R,R)-16 11\%

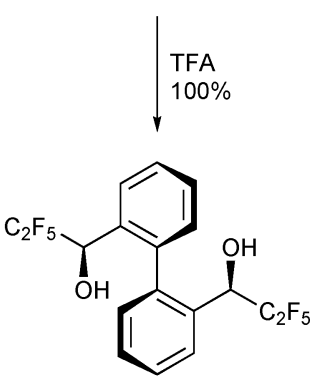

$(\mathrm{aS}, R, R)-17$
Scheme 4 Nickel-mediated diastereoselective $\mathrm{Ar}-\mathrm{Ar}$ homocoupling. ${ }^{12}$

While the Ullmann coupling and related reactions ${ }^{6}$ are useful sources of symmetrical biaryls, they are intrinsically less effective in the context of cross-coupling. Fortunately, by the 1980s various strategies were available for effecting aryl-aryl cross-coupling reactions using organometallic reagents as nucleophiles, and these could be rendered diastereoselective by the inclusion of homochiral components. Meyers and coworkers had established that, in appropriate circumstances, the methoxyl group of a 2-(2methoxyaryl)oxazoline is activated towards nucleophilic displacement by Grignard reagents, and were able to exploit this in biaryl synthesis by including chirality in the oxazoline moiety as illustrated in Scheme $5 .{ }^{13}$ Contemporaneously the alternative strategy of using a 2-(2-alkoxyaryl)oxazoline in which the departing alkoxyl group contained the required chirality was investigated by Wilson and Cram (Scheme 6). ${ }^{14}$ Both methods provided useful levels of diastereoselectivity. The results in Scheme 5 were rationalised by reference to intermediates of the forms $\mathbf{2 2}$ and $\mathbf{2 3}$, the rationale being that the former benefits from the coordination of the extra methoxyl group, but in the absence of this feature, the latter avoids steric compression of the peri-hydrogen $(\mathrm{H}-8)$ of the Grignard reagent. The results in Scheme 6 were rationalised on the basis of similar models, viz. $\mathbf{2 7}$ and 28, but with the influence of the substituents on the alkoxyl group superimposed as depicted.

Meyers' cross-coupling method was also shown to be effective with oxazolines derived from valinol, making it more convenient, and the coordination model shown in Scheme 5 was probed in studies involving various aromatic substrates. The results, shown in Scheme 7, ${ }^{11,15}$ confirm that in the Mg-assisted couplings, the electronic effect of an ortho-substituent is more influential than its steric size. It is proposed that the reactions in Scheme 7 proceed<smiles>[R]c1ccc2ccccc2c1[N+]Br</smiles>

18 (2 eq.)<smiles>COC[C@H]1N=C(c2ccc3ccccc3c2OC)O[C@@H]1c1ccccc1</smiles>

19 (1 eq.)

THF<smiles>[R]c1ccc2ccccc2c1-c1c(C2=N[C@@H](COC)[C@H](c3ccccc3)O2)ccc2ccccc12</smiles>

20<smiles>[R]c1ccc2ccccc2c1-c1c(C2=N[C@@H](COC)[C@H](c3ccccc3)O2)ccc2ccccc12</smiles>

21

\begin{tabular}{|ccrc|}
\hline $\mathbf{R}$ & Yield \% & $\mathbf{2 0 : 2 1}$ & Major \\
$\mathrm{H}$ & 80 & $87: 13$ & $R$ \\
$\mathrm{Me}$ & 68 & $76: 24$ & $R$ \\
$\mathrm{OMe}$ & 71 & $9: 91$ & $R$ \\
\hline
\end{tabular}

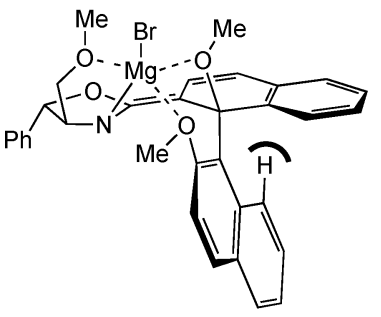

22

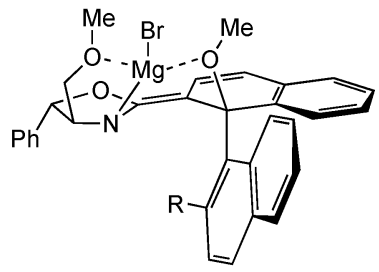

23
Scheme 5 Chiral oxazoline-mediated $\mathrm{Ar}-\mathrm{Ar}$ cross-coupling. ${ }^{13}$

most readily via an intermediate complex 33 , formed as a result of the nucleophile avoiding the isopropyl group during the coupling process and stabilised by coordination of the ortho-methoxyl substituent as indicated. When the ' $\mathrm{R}$ ' group can also coordinate to $\mathrm{Mg}$, the alternative pathway leading to the $(\mathrm{a} R)$-atropisomer 32 becomes competitive. This methodology has proved of enduring value, with applications that include a synthesis of the antileukemic lignan (-)-steganone $34,{ }^{16}$ and the preparation of a new series of substituted 2,2'-binaphthyls 35 by Sargent and coworkers. ${ }^{17}$<smiles>COc1cc2c(c(OC)c1OC)-c1cc3c(cc1C(=O)[C@@H]1COC(=O)[C@@H]1C2)OCO3</smiles>

34 (-)-steganone<smiles>[R]c1cc2ccccc2c(C2=NC([PH])CO2)c1-c1c([R])c([R])c2ccccc2c1[R]</smiles>

$35 \mathrm{R}^{\mathrm{n}}=\mathrm{H}, \mathrm{Me}, \mathrm{OMe}$
The strategy of using a chiral nucleofugic group as a stereocontrol element ( $c f$. Scheme 6) was extended by Miyano et al., who found that hindered ester groups were also able to activate the desired aromatic nucleophilic substitution process without themselves suffering attack by the Grignard reagent (Scheme 8). ${ }^{18}$ 
<smiles>[R]c1ccc2ccccc2c1[N+](=O)Br</smiles><smiles>CCC[C@H]1CC[C@@H](C)C[C@H]1Oc1c(C2=NC(C)(C)CO2)ccc2ccccc12</smiles>

18 (2 eq.)

24 (1 eq.)<smiles>[X]c1cc(C2=NC(P)CO2)c(OC)c(OC)c1[X]</smiles>

(S)-29 (1 eq.)<smiles>[X]c1cc([R])c([N+]([O])=O)c(OC)c1[X]</smiles>

30 (1.7 eq.)
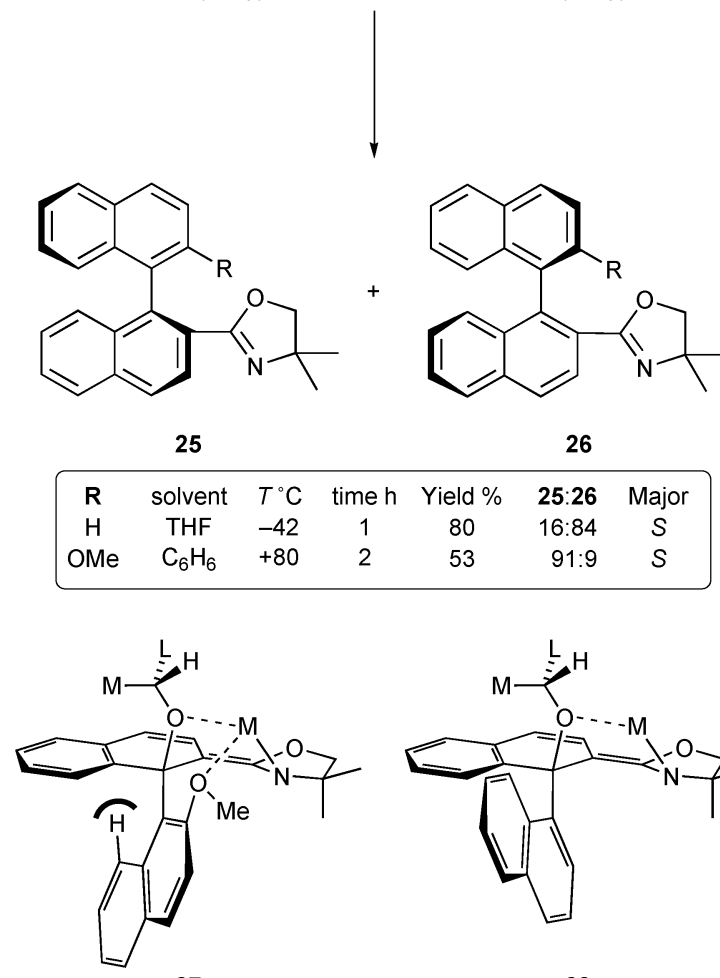

27

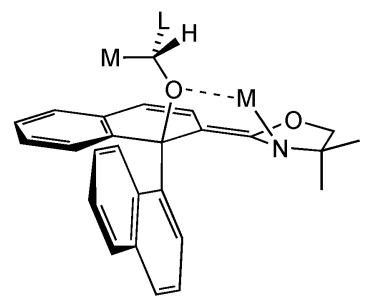

28

Scheme 6 Chiral nucleofuge-mediated $\mathrm{Ar}-\mathrm{Ar}$ cross-coupling. ${ }^{14}$

\section{Catalytic atroposelective aryl-aryl homocoupling reactions}

In the context of symmetrical biaryls, the distinctive redox properties of phenolic systems have allowed the development of synthetic methods based on oxidative coupling, from which have emerged various routes to BINOL 1 and its derivatives via the catalytic asymmetric oxidative coupling of 2-naphthols. ${ }^{1 f}$ The examples shown in Schemes 9 and 10 illustrate how oxygen can be used as the stoichiometric oxidant in the presence of a metal-based homochiral complex. The development of 1,5diazadecalin 39 as the source of chirality in the oxidative coupling of 40 to (aR)-41 (Scheme 9) was described by Kozlowski and coworkers. ${ }^{19}$ They proposed a mechanistic model based on the dissymmetric shielding of the re-face of the intermediate radical by the diamine unit, as depicted in $\mathbf{4 2}$, to account for their results. In the equivalent vanadium-based oxidative couplings, two groups used the amino acid-derived oxovanadium complexes 43 and 44 to generate a series of substituted binaphthols (Scheme 10). The coupling of $\mathbf{4 5}$ proved efficient using either catalyst, although the use of $\mathbf{4 3}$ gave $(\mathrm{a} R)-\mathbf{4 6}^{20}$ whereas the use of $\mathbf{4 4}\left(3 \mathrm{~mol} \%, 40-45^{\circ} \mathrm{C}\right.$, 7 d) gave the atropisomer (aS)-46 (96\% yield, $87 \%$ e.e. $){ }^{21}$ It is noteworthy that the catalyst $\mathbf{4 3}$ possesses a flexible biaryl axis, which offers advantages under the principles of tropoisomerism. ${ }^{22}$

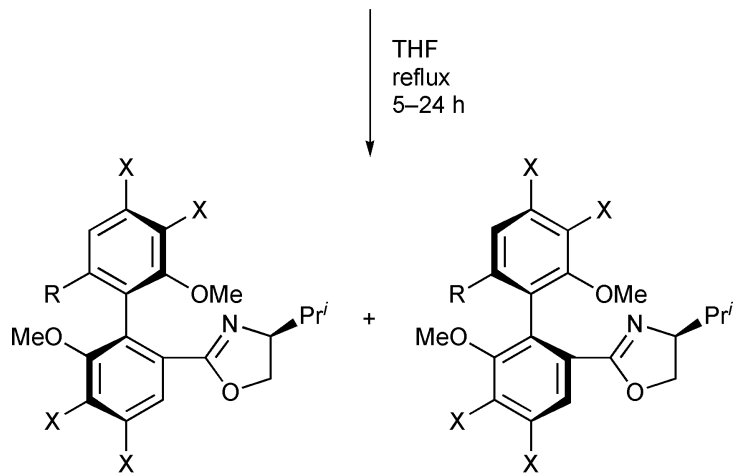

(aS,S)-31

\begin{tabular}{|llccc|}
\hline $\mathbf{R}$ & $\mathbf{X}$ & Yield \% & d.e. $\%$ & Major \\
$\mathrm{Me}$ & $\mathrm{H}$ & 79 & 80 & $\mathrm{~S}$ \\
$\mathrm{CH}_{2} \mathrm{OTBS}$ & $\mathrm{H}$ & 73 & 86 & $\mathrm{~S}$ \\
$\mathrm{CH}_{2}$ OMe & $\mathrm{H}$ & 75 & 20 & $R$ \\
1,3-dioxolan-2-yl & $\mathrm{H}$ & 90 & 60 & $R$ \\
1,3-dioxan-2-yl & $\mathrm{H}$ & 78 & 20 & $\mathrm{~S}$ \\
$\mathrm{Me}$ & $\mathrm{OMe}$ & 80 & 80 & $\mathrm{~S}$ \\
$\mathrm{CH}_{2} \mathrm{OTBS}$ & $\mathrm{OMe}$ & 90 & 96 & $\mathrm{~S}$ \\
$\mathrm{CH}_{2} \mathrm{OMe}$ & $\mathrm{OMe}$ & 56 & 56 & $\mathrm{~S}$ \\
$\mathrm{CH}_{2} \mathrm{OH}$ & $\mathrm{OMe}$ & 16 & 90 & $R$ \\
\hline
\end{tabular}

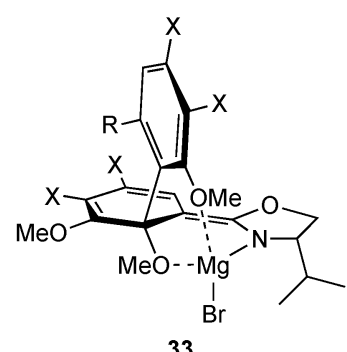

Scheme 7 Oxazoline-mediated synthesis of polymethoxylated biaryls. ${ }^{11,15}$

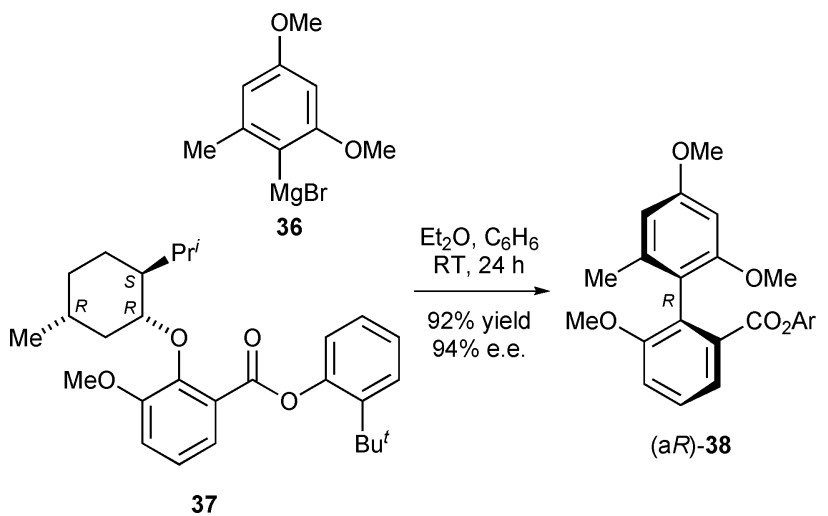

Scheme 8 Enantioselective biaryl synthesis from 2-menthoxybenzoates. ${ }^{18}$ 
<smiles>CC(=O)c1cc2ccccc2cc1O</smiles>
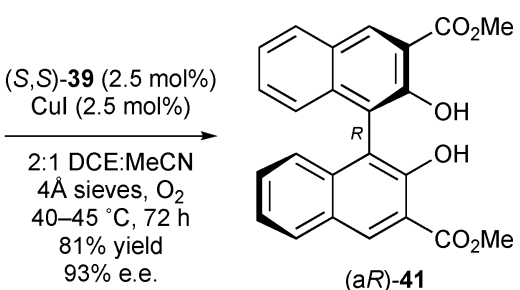

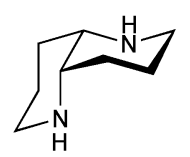

$(S, S)-39$

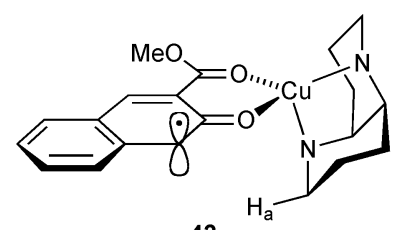

42
Scheme 9 Copper-mediated catalytic atroposelective coupling route to $41 .{ }^{19}$

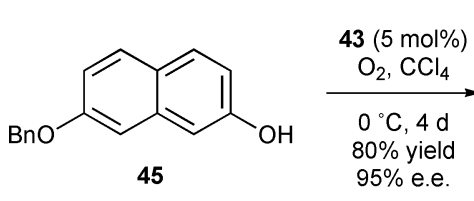

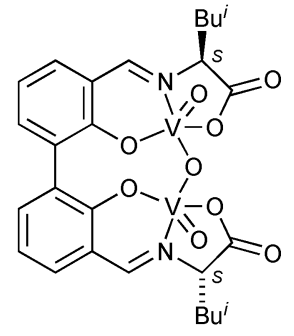

43<smiles>Oc1ccc2ccc(O)c(-c3c(O)ccc4ccc(OCc5ccccc5)cc34)c2c1</smiles>

$(\mathrm{aR})-46$

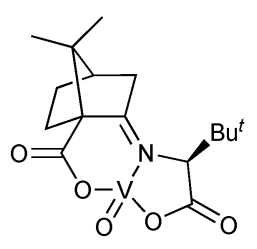

44

Scheme 10 Vanadium-mediated catalytic atroposelective coupling route to $41.20,21$

\section{Catalytic atroposelective aryl-aryl cross-coupling reactions}

The area of unsymmetrical biaryl synthesis was given new impetus with the emergence, during the 1970s, of a series of methods for the cross-coupling of haloarenes with organometallic reagents under transition-metal catalysis. The most enduring of these, first described in $1982,{ }^{23}$ is the combination of palladium as the catalytic metal with an arylboronic acid or ester as the organometallic reagent. Now known as the Suzuki-Miyaura reaction, ${ }^{24}$ this rose to prominence as the method of choice for biaryl synthesis because of its mildness, convenience and efficiency. The reaction tolerates a broad range of functional groups, can proceed in the presence of water, requires low catalyst loadings and produces no toxic by-products.

A simplified Suzuki-Miyaura reaction sequence is shown in Scheme 11. The cycle begins with step (i), the oxidative addition of the haloarene 47 to the catalytic $\mathrm{Pd}(0)$ species 48 to produce a $\mathrm{Pd}$ (II) intermediate 49. Step (ii) is the transmetallation of the arylboron reagent $\mathbf{5 0}$, as the $\mathrm{Nu}$-activated form $\mathbf{5 1}$, by the arylpalladium $\mathbf{4 9}$, which gives a trans-diarylpalladium species 52. Step (iii) is the isomerisation of trans-52 into cis-52 to set up step (iv), a reductive elimination which gives the biaryl product $\mathbf{5 3}$ and regenerates the catalyst 48.

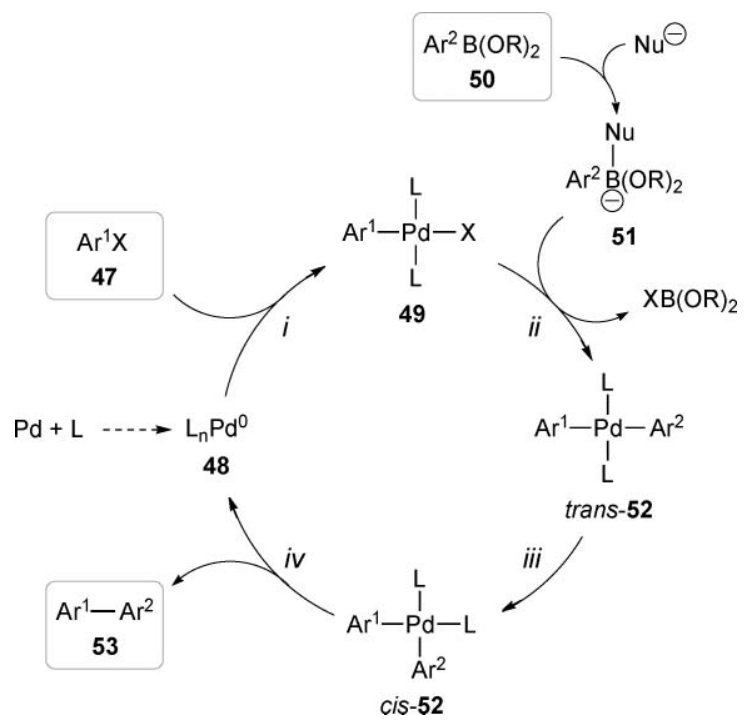

Scheme 11 The key steps in the Pd-catalysed cross-coupling route to a biaryl 53.

Key synthetic aspects of the reaction, in particular the effects of substituents, have been widely investigated and new generations of catalyst have been introduced in recent years. ${ }^{25}$ However, the situation represented in Scheme 11 is rendered complex by the superimposed effects of kinetics, thermodynamics and ligand exchanges that may attend any step in the cycle using any particular combination of reagents and solvents, so various mechanistic issues remain under scrutiny. These include the effects of steric bulk and electron donor capacity on the behaviour of ligands, ${ }^{26}$ the part played by base $(\mathrm{Nu})$ in the sequence, ${ }^{27}$ and the detailed mechanisms of oxidative addition ${ }^{28}$ and reductive elimination. ${ }^{29}$ Insight has been gained into the individual steps of the sequence by synthesising some of the putative intermediates. In a recent example, Osakada et al. prepared the cis-diarylpalladium complex 54 via the transmetallation of (2,6-difluorophenyl)boronic acid with 4-methoxyphenyl(iodo)Pd(TMEDA), and analysed the kinetics of thermally-induced reductive elimination to the biaryl 55 (Scheme 12). ${ }^{30}$
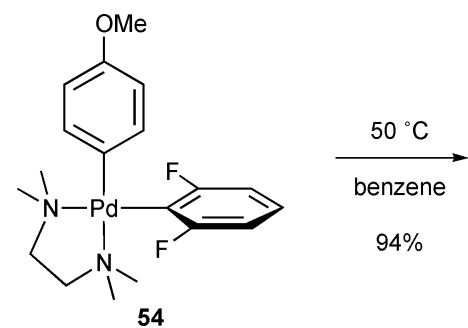<smiles>COc1ccc(-c2c(F)cccc2F)cc1</smiles>

Scheme 12 Direct biaryl formation via thermal reductive elimination. ${ }^{30}$

In principle, axis-selective Suzuki-Miyaura coupling is rendered possible by the inclusion of chirality in one or both the reaction partners, and Uemura and coworkers showed that the use of 


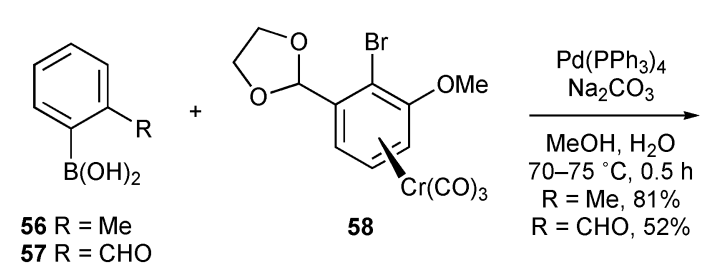<smiles>[R]c1ccccc1-c1c(C(=O)OCc2ccccc2)ccc(C(=O)OCc2ccccc2)c1OC</smiles><smiles>CC#CC=O</smiles><smiles>[R][C@H](I)[N+](=O)[O-]</smiles><smiles>COc1cccc(C2OCCO2)c1-c1ccccc1C</smiles>

$(\mathrm{a} R)-(-)-61$<smiles>COc1ccccc1-c1c(C(=O)O)cccc1C1OCCO1</smiles>

(aS)-60<smiles>COc1cccc(-c2c(OC)cccc2C2OCCO2)c1</smiles>

$(\mathrm{aS})-(+)-61$

Scheme 13 Suzuki-Miyaura reactions of chiral tricarbonyl(arene)chromium complexes. ${ }^{31}$

planar-chiral haloarenes is a particularly effective way to exploit this principle, as illustrated in Scheme $13 .{ }^{31}$ In this study it was found that coupling $\mathbf{5 6}$ or $\mathbf{5 7}$ with the chromium complex 58 gave the axially complementary biaryls (aR)-59 and (a $S$ )60 whose structures were confirmed via transformation into the enantiomeric biaryls (-)-61 and (+)-61. The seemingly opposite selectivity of the two coupling steps was rationalised by consideration of the cis-diarylpalladium(II) intermediates (cis-52 in Scheme 11) that might be involved. Of the possible structures, $\mathbf{6 2}$ has the R-group oriented syn to the less bulky (S) group and the tricarbonylchromium group anti to the nearest $\mathrm{PPh}_{3}$ group (Scheme 13, inset). Reductive elimination, expected to be rate-determining, can proceed most readily through $\mathbf{6 2}$ if the Rgroup rotates toward the $\mathrm{Cr}(\mathrm{CO})_{3}$ moiety and the $\mathrm{H}$-atom rotates towards the proximal $\mathrm{PPh}_{3}$ group, thereby avoiding non-bonding interactions between the latter and the R-group and producing 63; the formation of $\mathbf{5 9}$ is consistent with this rationale. The formation of $\mathbf{6 0}$ from the reaction of $\mathbf{5 7}$ with $\mathbf{5 8}$ can be attributed the isomerisation of the product 59 into the more stable $\mathbf{6 0}$ in which the $\mathrm{R}$ and (tricarbonyl)chromium groups are apart. The barrier to this type of isomerisation is significantly lower in the case of $\mathrm{R}=$ CHO. Uemura's methodology has since been adapted for use in approaches to biaryl natural products such as (-)-steganone $\mathbf{3 4} .^{32}$

Catalysed cross-coupling between reaction partners with existing central chirality is a potentially common scenario in the synthesis of atropisomeric natural products, but a pair of fragments may not be predisposed towards coupling in the desired sense. One way to cope with this situation is to equip one of the coupling partners with an 'internal ligand' that can direct the coupling reaction. The viability of this strategy was illustrated by Lipshutz and Keith as they sought a route to the alkaloid korupensamine A. ${ }^{33}$ The key coupling step (Scheme 14) involved the haloarene 64, in which a 2-(diphenylphosphino)benzoate group served as the directing ligand, and the boronate $\mathbf{6 5}$. The reaction, carried out in the presence of $\mathrm{PdCl}_{2}(\mathrm{dppf})$ and 2,6-di-t-butyl-4-methylphenol (BHT), gave the atropisomer 67 exclusively. This outcome can be rationalised on the basis of an intermediate diarylpalladium species 68 (Scheme 14, inset), through which reductive elimination to give $\mathbf{6 7}$ can occur with the bulk of the naphthalene moiety and the dppf ligand $66 \mathrm{kept}$ apart throughout.

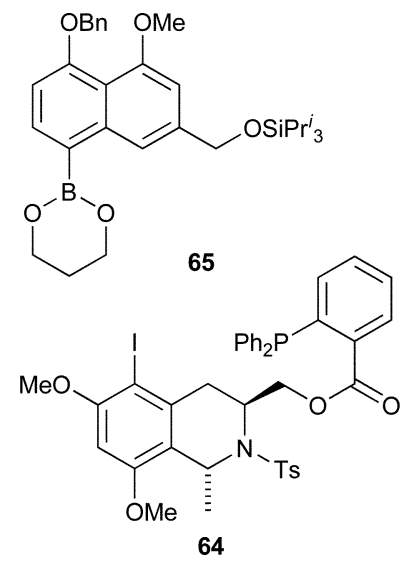

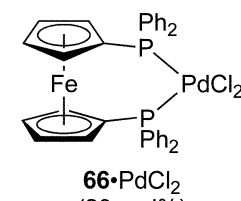

$(20 \mathrm{~mol} \%)$

$\mathrm{BHT}(0.7$ eq. $)$ $\mathrm{K}_{3} \mathrm{PO}_{4}$, DMF $117^{\circ} \mathrm{C}, 5 \mathrm{~h}$

$81 \%$

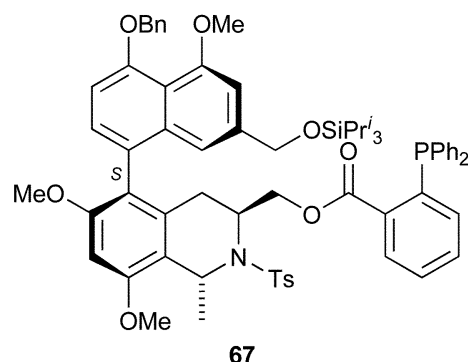

67

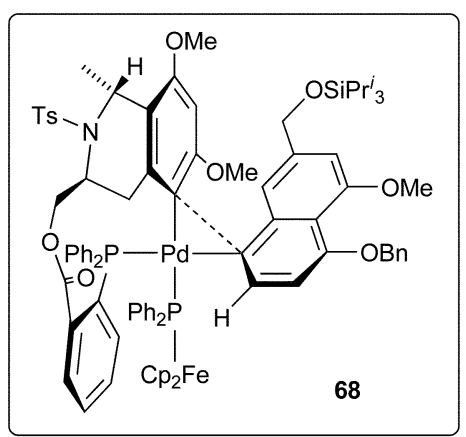

Scheme 14 Suzuki-Miyaura coupling with intramolecular phosphine coordination. ${ }^{33}$ 
Intramolecular coordination to palladium has also been invoked as a control element in atroposelective arylations of haloarenes bearing heteroatom-substituted $o$-alkyl groups. For example, Baudoin et al. found that the 1-(o-iodoaryl)ethanol 69 reacted with the pinacol boronate $70(\mathrm{R}=\mathrm{TES})$ to give the corresponding biaryl $\mathbf{7 2}$ with essentially complete axis control (Scheme 15). ${ }^{34}$ The sense of the selectivity, which was lower when less bulky $\mathrm{R}$ groups were used, is consistent with reaction via a diarylpalladium species 73, in which the methyl group of the Pdcoordinated hydroxyethyl side-chain avoids a steric clash with the $\mathrm{CH}_{2} \mathrm{OR}$ group of the other aryl substituent. In a parallel study, Broutin and Colobert observed coordination effects involving both the alpha (benzylic) and beta positions of the $o$-alkyl sidechain of the haloarene (Scheme 16). ${ }^{35,36}$ Thus, coupling iodoarenes<smiles>C[C@@H](O)c1cc2c(cc1I)OCO2</smiles>

(R)-69 (1.0 eq.)<smiles>CC1(C)OBOC1(C)C</smiles><smiles>[R]Cc1cc(OC)c(OC)c(OC)c1Br</smiles>
70 (1.5 eq.)

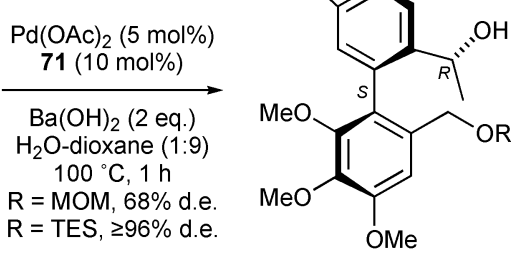

$(\mathrm{aS}, \mathrm{R})-\mathbf{7 2}$

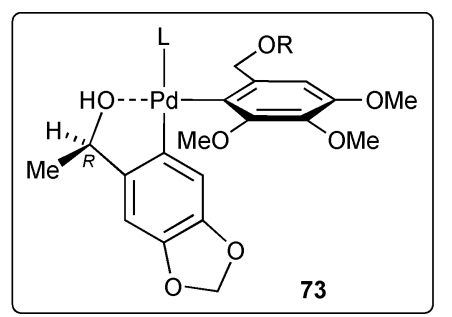

Scheme 15 Suzuki-Miyaura coupling of (2-iodoaryl)ethanol derivatives. $^{34}$
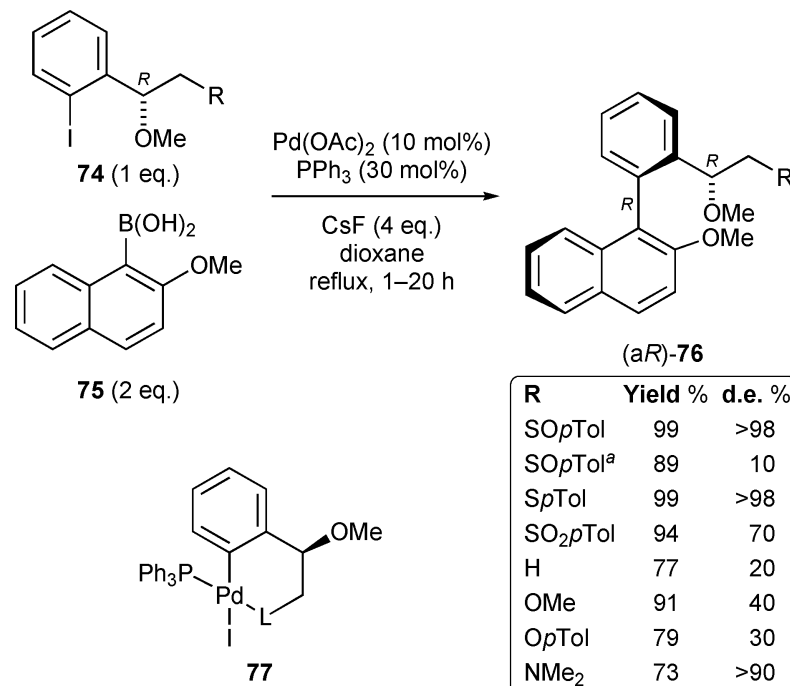

\begin{tabular}{|c|c|c|}
\hline \multicolumn{3}{|c|}{$(a R)-76$} \\
\hline $\mathbf{R}$ & Yield \% & d.e. $\%$ \\
\hline sopTol & 99 & $>98$ \\
\hline sOpTol $^{a}$ & 89 & 10 \\
\hline SpTol & 99 & $>98$ \\
\hline $\mathrm{SO}_{2} p \mathrm{Tol}$ & 94 & 70 \\
\hline $\mathrm{H}$ & 77 & 20 \\
\hline $\mathrm{OMe}$ & 91 & 40 \\
\hline OpTol & 79 & 30 \\
\hline $\mathrm{NMe}_{2}$ & 73 & $>90$ \\
\hline
\end{tabular}

Scheme 16 Suzuki-Miyaura coupling of substituted (2-iodoaryl)ethanol derivatives. ${ }^{35,36}$ $\mathbf{7 4}$ with the naphthylboronic acid $\mathbf{7 5}$ gave the biaryls $\mathbf{7 6}$ in good yield but with levels of atroposelectivity that varied with the coordinating ability of the $\mathrm{R}$ group, suggesting the participation of intermediates of the form 77 . The sulfoxide $74(\mathrm{R}=\mathrm{SO} p \mathrm{Tol})$ possesses two stereogenic centres, and it was found that the coupling atroposelectivity was much lower $(10 \%$ d.e. $)$ with the C$1^{\prime}(S)$ epimer than with the corresponding sulfone $74\left(\mathrm{R}=\mathrm{SO}_{2} p \mathrm{Tol}\right)$ ( $70 \%$ d.e.), indicating that the benzylic stereochemistry was the dominant factor in this case. ${ }^{35}$

\section{Aryl-aryl cross-coupling using homochiral catalysts}

In 1988 Hayashi and coworkers set a formidable standard for catalytic atroposelective cross-coupling of haloarenes and arylmetals. Their system is illustrated in Scheme 17 with the coupling of $\mathbf{7 8}$ and 79 using a nickel catalyst derived from the ferrocenylphosphine ligand 80, which gave the binaphthyl $(R)-\mathbf{8 1}\left(95 \%\right.$ e.e.). ${ }^{37}$ The phosphine ligand $\mathbf{8 0}$, which could be recovered from the reaction and reused, incorporated an alkoxy group that proved essential for high selectivity. This was attributed to its ability to coordinate to magnesium during the formation of a diarylnickel species via a transmetallation step equivalent to (ii) in Scheme 11.<smiles>Cc1ccc2ccccc2c1[N+](C)(Br)Br</smiles>

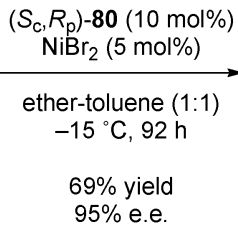

79 (1.3 eq.)<smiles>Cc1ccc2ccccc2c1-c1c(C)ccc2ccccc12</smiles>

$(R)-81$
Scheme 17 Asymmetric catalysis of Ar-Ar cross-coupling. ${ }^{37}$

Homochiral ligands were later used to control the atroposelectivity of diastereoselective Suzuki-Miyaura reactions (i.e., those in which central chirality is present in one or both of the coupling partners). For example, in the course of their studies directed towards the total synthesis of vancomycin $\mathbf{4}$, Nicolaou and coworkers found that the Pd-catalysed coupling of $\mathbf{8 2}$ and 83 in the presence of $(S)$-BINAP 1 gave the biaryl 84 with high atroposelectivity (Scheme 18). ${ }^{38}$ No axial selectivity was observed using triphenylphosphine as the added ligand, indicating that the reaction was devoid of any bias due to the central chirality in $\mathbf{8 3}$.

Recent studies have revealed the potential for interplay between catalyst structure and pre-existing central chirality in SuzukiMiyaura reactions. The coupling of $\mathbf{8 5}$ and $(S)$-86 was carried out in the presence of different stereoisomers of the ligands $\mathbf{1}$ and $\mathbf{8 7 -}$ 89, and in all cases the presence of the homochiral ligand favoured the formation of the biaryl (aR)-90 (up to 50\% d.e.) (Scheme 19). ${ }^{39}$ It is intriguing that each enantiomer of $\mathbf{1}$ and $\mathbf{8 9}$ should favour the same $(\mathrm{a} R)$ sense of coupling, and that no ligand was able to reinforce the existing predisposition towards pro-(a $S$ ) coupling ( $c f$. entry 9) under the conditions used. Moreover it was shown that the atroposelectivity of Suzuki-Miyaura coupling reactions can be reversed by changing the ligand-palladium ratio. ${ }^{40}$ 
<smiles>COc1cc2c(c(OC)c1)B(O)OC2</smiles>

82 (2 eq.)<smiles>COc1cccc(C[C@H](Cc2ccc(Oc3cccc(CC(=O)N[C@H](C(C)=O)c4ccc(OC)c(I)c4)c3)cc2)NC(=O)C(C)C)c1</smiles>

83 (1 eq.)

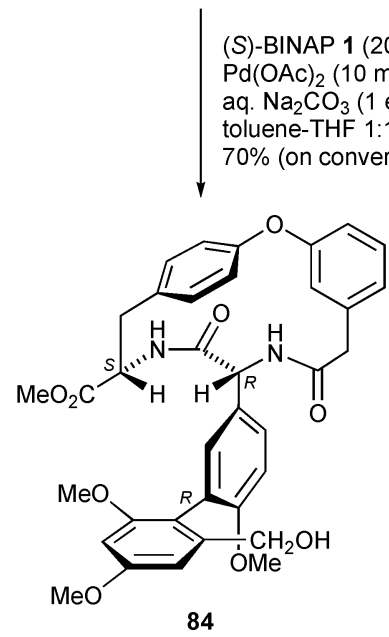

Scheme 18 Atroposelective catalysis of Suzuki-Miyaura coupling using BINAP $1^{38}$

The first examples of asymmetric Suzuki-Miyaura crosscoupling of achiral aryl reagents, utilising $\mathbf{8 9}^{41}$ and $\mathbf{9 1}^{42}$ as the respective catalytic ligands, were reported in 2000 , and a variety of alternative ligands such as $\mathbf{9 2},{ }^{43} \mathbf{9 3}^{43}$ and $\mathbf{9 4}{ }^{44}$ have also been screened as catalysts since then.

Cammidge and Crépy screened twelve ligands, including amines and $P$-chiral phosphines, and a variety of reaction conditions for the synthesis of binaphthyls, obtaining their best result using the ligand 89 (Scheme 20). ${ }^{41}$ They also made some mechanistically intriguing observations, e.g. that the predominating atroposelectivity<smiles>COc1ccc(OC)c2c(OC)cc(C)cc12</smiles>

85 (1.5 eq.)<smiles>COc1cc(OC)c2c(c1I)C[C@@H](C)N=C2C</smiles>

86 (1.0 eq.)

$\mathrm{Pd}_{2}(\mathrm{dba})_{3}$

Ligand $\mathrm{L}^{*}$

$\mathrm{NaHCO}_{3}, \mathrm{H}_{2} \mathrm{O}$

toluene, reflux, 9-16 $\mathrm{h}$

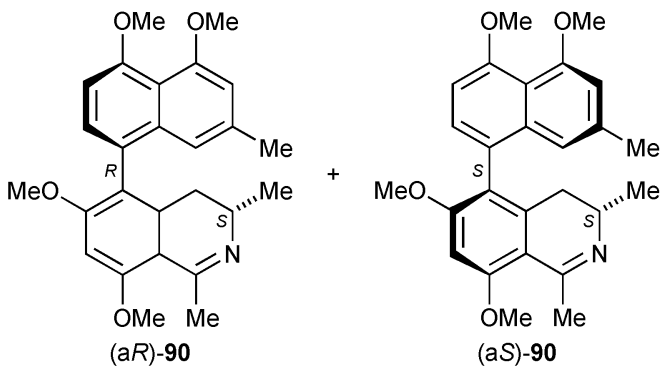

\begin{tabular}{|cccccc|}
\hline entry & Ligand $\mathrm{L}^{*}$ & $\mathrm{~L}^{*} \mathrm{~mol} \%$ & $\mathrm{Pd}$ mol\% & Yield \% & $(\mathrm{a} R):(\mathrm{aS})$ \\
1 & $(\mathrm{a} R, R)-87$ & 20 & 5 & 65 & $63: 37$ \\
2 & $(\mathrm{a} R, S)-87$ & 20 & 5 & 89 & $57: 43$ \\
3 & $(\mathrm{a} R, R)-88$ & 20 & 5 & 44 & $67: 33$ \\
4 & $(\mathrm{a} R, S)-88$ & 20 & 5 & 58 & $62: 38$ \\
5 & $\left(R_{\mathrm{c}}, \mathrm{S}_{\mathrm{p}}\right)-89$ & 55 & 50 & 42 & $75: 25$ \\
6 & $\left(\mathrm{~S}_{\mathrm{c}}, R_{\mathrm{p}}\right)-89$ & 55 & 50 & 34 & $51: 49$ \\
7 & $(R)-1$ & 30 & 20 & 46 & $61: 39$ \\
8 & $(S)-1$ & 30 & 20 & 50 & $75: 25$ \\
9 & $\mathrm{Pd}\left(\mathrm{PPh}_{3}\right)_{4}$ & & 10 & 51 & $45: 55$ \\
\hline
\end{tabular}

Scheme 19 Atroposelection with interplay of catalyst structure and steric predisposition. $^{39}$

can be inverted by changing the boronate ester from the ethylene glycol derivative 96a to the corresponding pinacol derivative $\mathbf{9 6 b}$, which contributes to the evidence for transmetallation being the critical step as far as asymmetric induction is concerned. Yin and Buchwald prepared a series of hindered binaphthyl-derived ligands and found optimum coupling conditions (solvent, base, etc.) with 91 in combination with $\mathrm{Pd}_{2} \mathrm{dba}_{3}$ at low catalyst loadings<smiles>Cc1ccccc1-c1ccccc1P(C)(=O)c1ccccc1</smiles>

71<smiles>CCOc1ccc2ccccc2c1-c1c(NC)ccc2ccccc12</smiles>

(S)-91

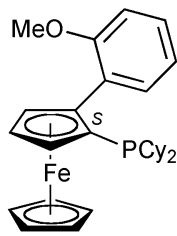

$\left(S_{\mathrm{p}}\right)-92$

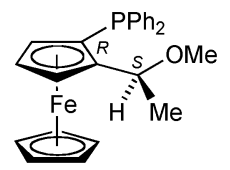

$\left(S_{\mathrm{c}}, R_{\mathrm{p}}\right)-80$

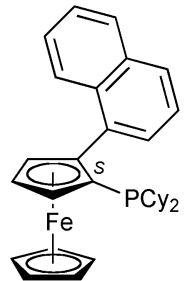

$\left(S_{p}\right)-93$<smiles>[R]c1cc([R])c(-c2c(CN(C)[C@H](C)c3ccccc3)ccc3ccccc23)c(P)c1</smiles>

$(\mathrm{a} R, R)-87(\mathrm{R}=\mathrm{OMe})$ $(\mathrm{a} R, R)-88(\mathrm{R}=\mathrm{Me})$<smiles>O=C(O)c1ccc2ccccc2c1C(c1ccccc1)c1cccc2ccccc12</smiles>

(S)-94 


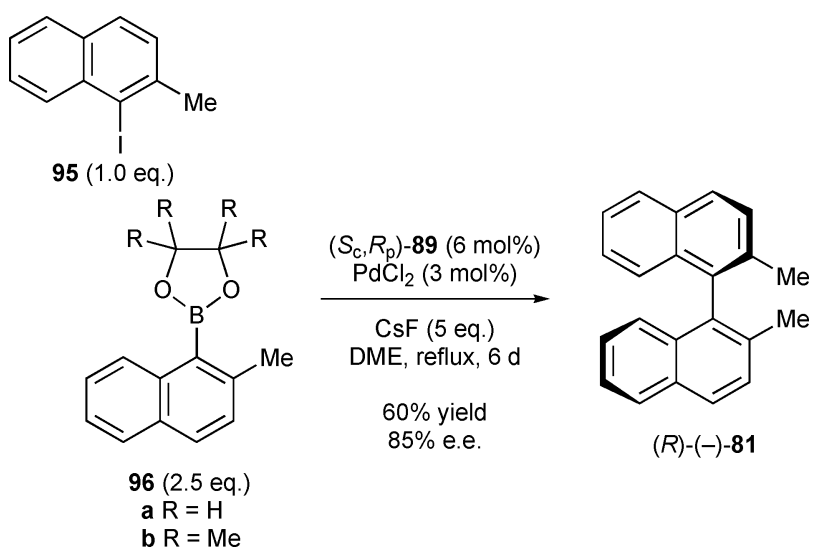

Scheme 20 Asymmetric biaryl coupling using the ligand 89. ${ }^{41}$

(Scheme 21). ${ }^{42}$ Later studies along similar lines led to the new ferrocenylphosphine ligands 92 and 93 (Scheme 22) (33 $^{43}$ and the use of a cationic palladium species derived from $(S)$-Cy-BINAP 94 as a catalyst (Scheme 23). ${ }^{44}$<smiles>CCOP(=O)(OCC)c1ccc2ccccc2c1Br</smiles>

97 (1.5 eq.)

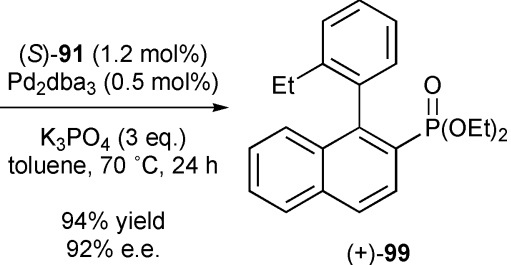

$(+)-99$
Scheme 21 Asymmetric biaryl coupling using the ligand $91 .^{42}$

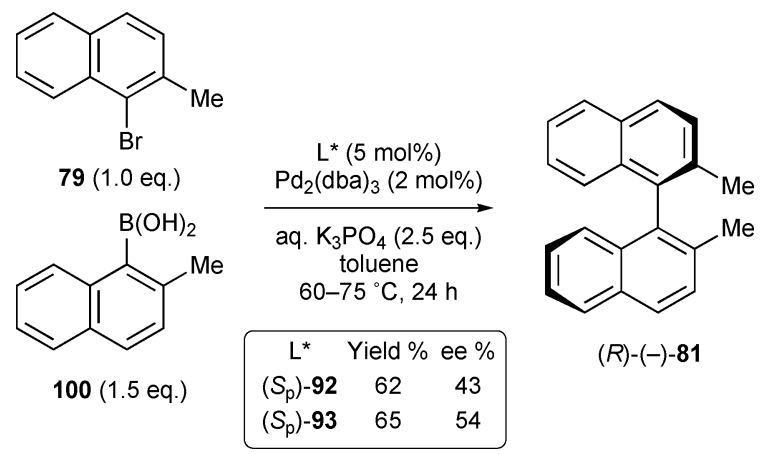

Scheme 22 Asymmetric biaryl coupling using the ligands 92 and $93 .{ }^{43}$

In their preparation of an analogue of the tubulin-binding agent rhazinilam, Baudoin and coworkers screened several SuzukiMiyaura catalysts for use in coupling 104 with 105, and obtained a useful result with the Yin-Buchwald system, which gave the desired biaryl 106 with $40 \%$ e.e. (Scheme 24). ${ }^{45}$ They suggested that the sense of induction observed in this reaction was compatible with the participation of a five-membered palladacycle intermediate 107, which could be formed with minimised steric interactions between the substituents both before and during the transmetallation step leading to it. Crystallographic evidence for<smiles>COc1ccc2ccccc2c1Br</smiles>

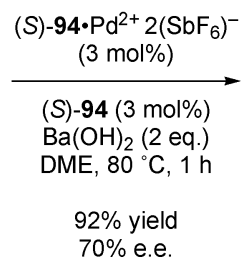

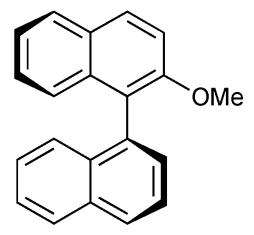

(S)-103
Scheme 23 Asymmetric biaryl coupling using a cationic Pd complex. ${ }^{44}$
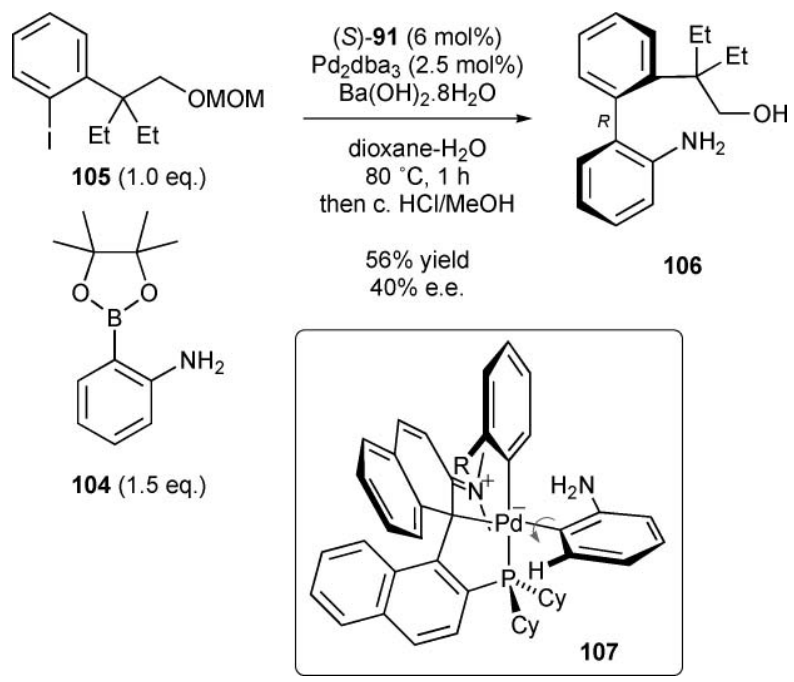

Scheme 24 Synthetic application of the catalyst $91 .^{45}$

bonding of the type shown in the palladacycle ring of $\mathbf{1 0 7}$ was originally obtained by Kocovsky and coworkers. ${ }^{46}$

\section{Tether-controlled intramolecular aryl-aryl coupling}

Various aryl-aryl coupling methods have been adapted for atroposelective biaryl synthesis based on the use of chiral tethers of different lengths to link the reacting aryl groups. In a study directed towards the synthesis of vancomycin 4, Evans and coworkers provided a graphic demonstration of how differences in the structure of the tethering chain could affect the outcome of an aryl-aryl coupling, in this case one involving the closure of a 12-membered ring (Scheme 25) ${ }^{47}$ Although the two substrates 108 and 109 differ in configuration at only one stereogenic centre, they undergo vanadium-catalysed oxidative coupling with high but opposite atroposelectivity. The minimisation, during ring closure, of $A^{(1,3)}$ strain between the acetamido and nearby methoxyl groups probably accounts for this selectivity.

Lipshutz and coworkers also used a tether strategy to close an eight-membered ring using the nickel-based coupling process shown in Scheme 26.8 ${ }^{48}$ The tether connecting the two iodoaryl rings in 112 was derived from 1,4-di- $O$-benzyl-D-threitol.

The palladium-mediated closure of a seven-membered ring was used by Kündig and coworkers to prepare the axially- and centrally-chiral azepine $\mathbf{1 1 5}$ from the bis(aryltriflate) 114 via an intramolecular Stille coupling process (Scheme 27). The corresponding meso-amine was prepared using a similar sequence. ${ }^{49}$ 
<smiles>[R1]C(C(=O)N[C@H](C(=O)N[C@H](C(=O)OC)c1ccc(OC)cc1OC)[C@@H](O)c1cc(Cl)c(OC(=O)c2ccccc2)c(Cl)c1)c1cc(OC)cc(OC)c1</smiles>

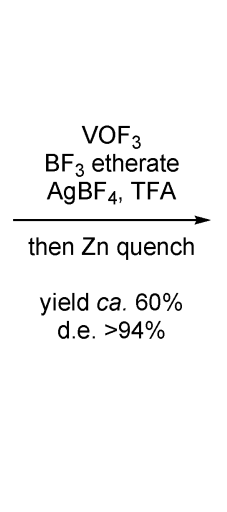

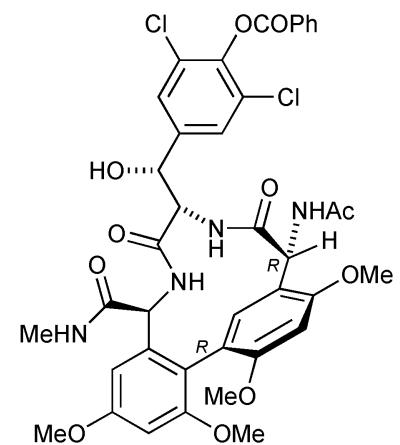

$(\mathrm{a} R)-110$ (from 108)

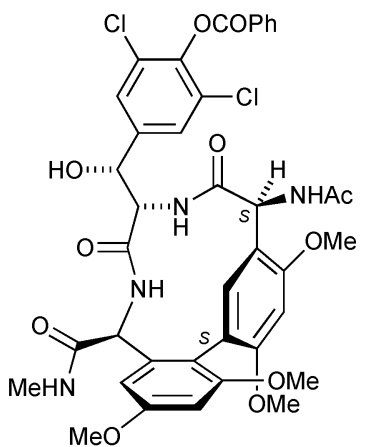

(aS)-111 (from 109)

Scheme 25 Atroposelective closure of twelve-membered rings. ${ }^{47}$

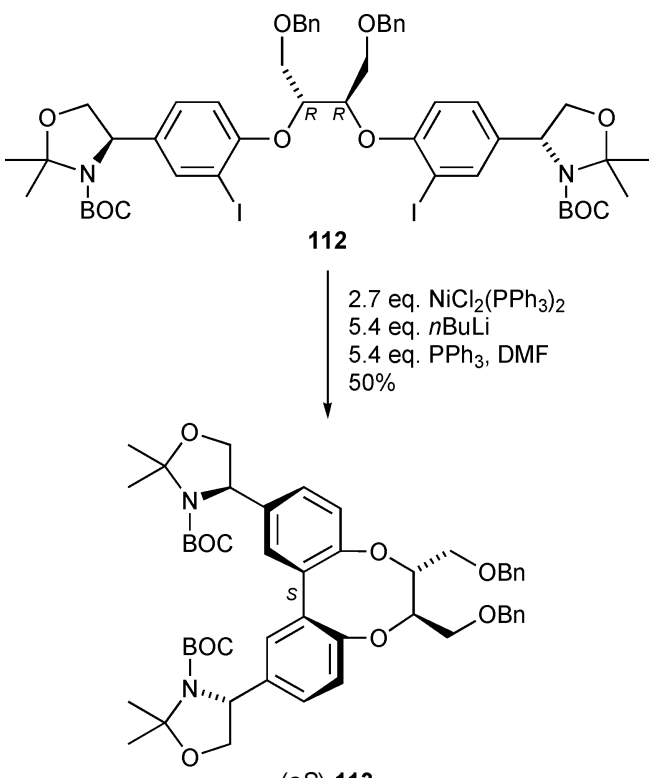

(aS)-113

Scheme 26 Atroposelective closure of an eight-membered ring. ${ }^{48}$<smiles>CCOc1ccccc1[C@@H](C)N(C(=O)C(F)(F)F)[C@@H](C)c1ccccc1OC</smiles>
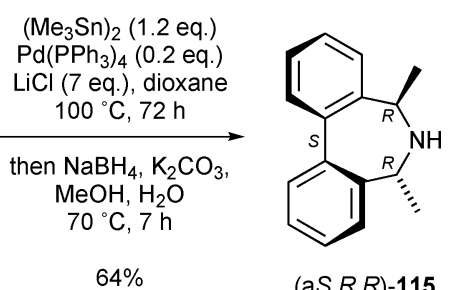

$(\mathrm{aS}, R, R)-115$

$(R, R)-114$

Scheme 27 Atroposelective closure of a seven-membered ring. ${ }^{49}$

Various groups have successfully combined the use of coppermediated oxidative coupling of iodoarenes with tether-controlled atroposelection. For example the diether 116, prepared from $(R, R)$-pentane-2,4-diol, was atroposelectively transformed into 117 via sequential iodine-lithium exchange, cupration and oxidation steps (Scheme 28). ${ }^{50}$ A similar coupling procedure has been adapted by Schreiber and coworkers for the synthesis of biaryls incorporating nine- and ten-membered rings, based on the use of starting materials with tethers derived from readily-available chiral amino alcohols (Scheme 29). ${ }^{51,52}$

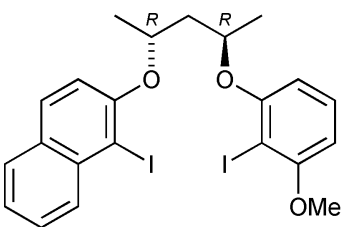

$(\mathrm{a} R, S)-116$

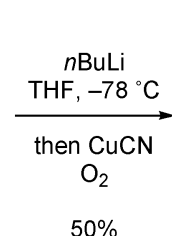

$50 \%$

Scheme 28 Atroposelective closure of a nine-membered ring. ${ }^{50}$<smiles>CN(Cc1ccccc1I)[C@H](COCc1ccccc1I)Cc1ccccc1</smiles>

(S)-118

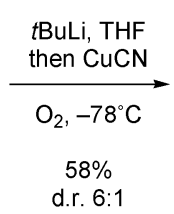

$58 \%$
Scheme 29 Atroposelective closure of a ten-membered ring. ${ }^{51}$

In an extension of their use of threitol-derived tethers to control aryl-aryl coupling reactions, Lipshutz and coworkers prepared the bis(naphthyl ether) $\mathbf{1 2 0}$ using a chiral tether derived from (E)-3-hexene-1,6-dioic acid via asymmetric dihydroxylation, and effected its intramolecular oxidative coupling to $\mathbf{1 2 1}$ using copper(II) chloride in the presence of racemic $\alpha$-methylbenzylamine (Scheme 30). ${ }^{53}$ The product $\mathbf{1 2 1}$ has the same core as the versatile ligand 2-amino-2'-hydroxy-1,1'-binaphthyl (NOBIN). ${ }^{1 e}$

\section{Dynamic atroposelective convergence of pre-formed biaryls}

As an alternative to the various atroposelective aryl-aryl coupling routes to enantiopure biaryls, the strategy of starting with a readymade biaryl and converging to a single atropisomer has much to commend it, especially if the ultimate source of chirality is used in catalytic, rather than stoichiometric, quantities. Such a system has been developed and refined by Bringmann and coworkers, based on the dynamic kinetic resolution of 1,1'-biaryls which incorporate a 2,2'-lactone bridge. The principles and practice of Bringmann's 'lactone' method have been thoroughly reviewed, 5,54 and two examples are provided here. 
<smiles></smiles>

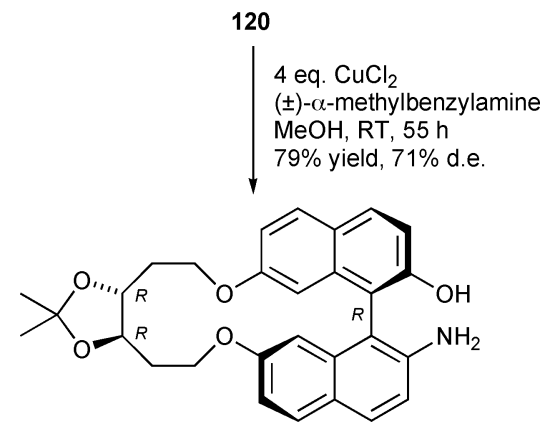

$(\mathrm{a} R)-121$

Scheme 30 Tethered phenolic oxidative aryl-aryl coupling. ${ }^{53}$

The essential features of the method are illustrated by the reduction of the bridged biaryl lactone $\mathbf{1 2 2}$ using the oxazaborolidine-borane reagent $(S)$-123 (Scheme 31$){ }^{55}$ The biaryl axis of the lactone $\mathbf{1 2 2}$ is not configurationally stable, the compound existing as a mixture of rapidly interconverting non-planar stereoisomers $(\mathrm{a} R)-\mathbf{1 2 2}$ and $(\mathrm{a} S)-\mathbf{1 2 2}$. The MM2-minimised structure of $(\mathrm{a} R)-122$ (Scheme 31, inset) reveals the degree of twist in the lactone moiety. Because the reducing agent (S)-123 is homochiral, the transition states for the reduction of the interconverting forms of $\mathbf{1 2 2}$ are diastereoisomeric and dynamic kinetic resolution is possible. The isomer $(\mathrm{a} R)$-122 is reduced much more rapidly than $(\mathrm{a} S)$-122, bringing about the observed convergence to $(\mathrm{a} R)-\mathbf{1 2 4}$, which is configurationally stable.<smiles>Cc1cc(C)c2c(c1)oc(=O)c1ccc3ccccc3c12</smiles>

(aS)-122<smiles>Cc1cc(C)c2c(c1)oc(=O)c1ccc3ccccc3c12</smiles>

$(\mathrm{aR})-122$
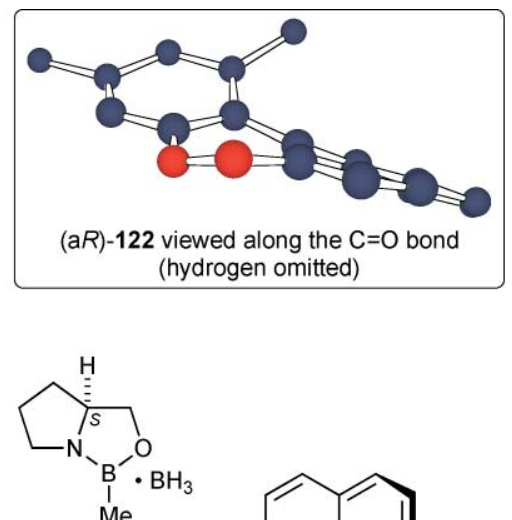

(S)-123<smiles></smiles>

$94 \%$ yield $97 \%$ e.e.

Scheme 31 Enantioselective reduction of the lactone 122. ${ }^{55}$

Many biaryl natural products incorporate carbon and oxygen substituents adjacent to the aryl-aryl link, and the lactone method can be a particularly convenient source of atropisomerically pure precursors. For example, the synthesis of a masked AB-biaryl fragment of vancomycin 4 was carried out as in Scheme 32.56 The lactone $\mathbf{1 2 5}$ was configurationally unstable, and could be reduced with high selectivity to $\mathbf{1 2 6}$, in which the chlorine atoms served to stabilise the axis. The structure of $\mathbf{1 2 6}$ was confirmed by dechlorination to 127 , which was configurationally labile but sufficiently long-lived for confirmation of its identity. This route to the vancomycin biaryl provides an interesting comparison with alternative cross-coupling strategies ( $c f$. Schemes 18 and 25).

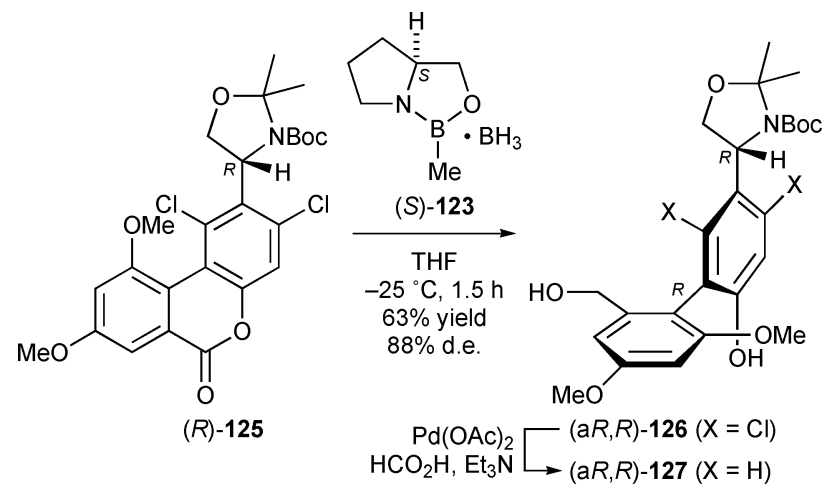

Scheme 32 Application of Bringmann's lactone method in the vancomycin series. ${ }^{56}$

Another dynamic kinetic resolution process has developed by Hayashi and coworkers, who have shown that axially chiral biaryls are accessible via the nickel-catalysed cross-coupling of substituted dibenzothiophenes with organomagnesium reagents in the presence of a chiral ligand. ${ }^{57}$ In the example shown in Scheme 33, an excellent yield of the binaphthyl $(S)-\mathbf{1 2 9}$ is obtained by treating the dinaphthothiophene $\mathbf{1 2 8}$ with $p$-tolylmagnesium bromide in the presence of 0.03 equivalents of a nickel-phosphine complex generated in situ from bis(1,5-cyclooctadiene)nickel(II) and the oxazoline ligand $(S)-\mathbf{1 3 0}$. The reaction is presumed to involve the intermediate formation of a pair of nickelacycles 131, which are configurationally unstable and in dynamic equilibrium (as with the lactone 122). The diastereoisomeric nature of these intermediates allows the addition of the organomagnesium reagent (transmetallation) to proceed with dynamic kinetic selectivity<smiles>c1ccc2c(c1)ccc1sc3ccc4ccccc4c3c12</smiles>

128<smiles>CC(C)[C@@H]1COC(c2ccccc2Pc2ccccc2)=N1</smiles>

(S)-130

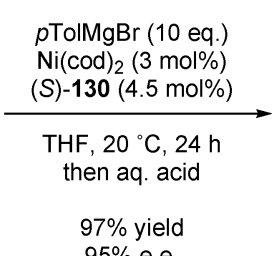

$95 \%$ e.e.<smiles>c1ccc2c(c1)N[14CH2]c1ccc3ccccc3c1-2</smiles>

(S)-131<smiles>Oc1ccc2ccccc2c1-c1c(S)ccc2ccccc12</smiles>

(S)-129<smiles>c1ccc2c(c1)NSc1ccc3ccccc3c1-2</smiles>

$(R)-131$
Scheme 33 Nickel-catalysed asymmetric cross-coupling of a dinaphthothiophene. ${ }^{57}$ 
which, under the conditions shown, favours reaction via the atropisomer $(S)$-131. The stereochemical outcome of this type of reaction is dependent on the organomagnesium reagent used, indicating that stereoselection occurs during or after the transmetallation event. ${ }^{57}$

Two other convergence strategies for biaryl axis control, both extensions of the chiral tether principle discussed earlier, have been introduced. The first of these, desymmetrisation, is illustrated by another application of the threitol unit which featured in Scheme 26. Harada and coworkers desymmetrised the prochiral tetrahydroxybiaryl $\mathbf{1 3 2}$ by sequential etherification with 1,4-O-dibenzyl-L-threitol 133 under Mitsunobu conditions (Scheme 34). ${ }^{58}$ The product 134 can be transformed into a variety of functionalised biaryls by further manipulation of the phenolic hydroxyl groups. A second convergence method is axis induction via the formation of fused oxazolidine lactams. ${ }^{59,60}$ The condensation of ester-aldehyde $\mathbf{1 3 5}$ with an amino alcohol $(S)$ 136 under dehydrating conditions gives the corresponding fused lactam $\mathbf{1 3 7}$ in which the chirality of $\mathbf{1 3 6}$ is relayed to the biaryl axis via the newly-generated benzylic stereocentre (Scheme 35). ${ }^{59,61}$ On treatment with acid, the lactams 137 undergo equilibration with the less strained diastereisomers 138, the benzylic centre-axis complementarity being fully maintained. The lactam method was used by Levacher and coworkers to prepare some novel fused biaryls, e.g. the 2-(1-naphthyl)pyridine derivative $139 .{ }^{60}$ Methods for manipulating lactams of the form 137 with retention of the axial chirality are under investigation ${ }^{61}$ and an alternative procedure for lactam formation is available. ${ }^{62}$<smiles>Oc1cccc(O)c1-c1c(O)cccc1O</smiles>

132

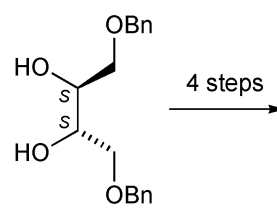

$(S, S)-133$<smiles>Oc1cccc2c1-c1c(O)cccc1[C@H](COCc1ccccc1)[C@@H](COCc1ccccc1)O2</smiles>

$(\mathrm{aS}, R, R)-134$
Scheme 34 Desymmetrisation of 2,2',6,6'-tetrahydroxybiphenyl. ${ }^{58}$<smiles>CC(=O)c1ccccc1-c1ccccc1C=O</smiles><smiles>[2H][C@@H](N)CO</smiles>

(S)-136 $\mathrm{R}=$ alkyl, ary
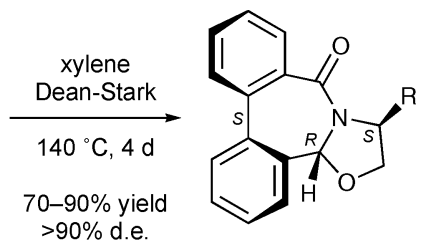

$(\mathrm{aS}, R, S)-137$

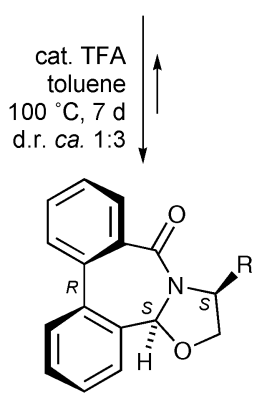

$(a R, S, S)-138$
Scheme 35 Formation and equilibration of fused biaryl lactams. ${ }^{59,61}$

\section{Biaryl synthesis using atroposelective annulation sequences}

Several groups have developed methods for the construction of one of the aromatic rings of a biaryl via an annulation sequence with provision for control over the final axial configuration of the product. Some of these approaches are illustrated in Scheme 36-40.

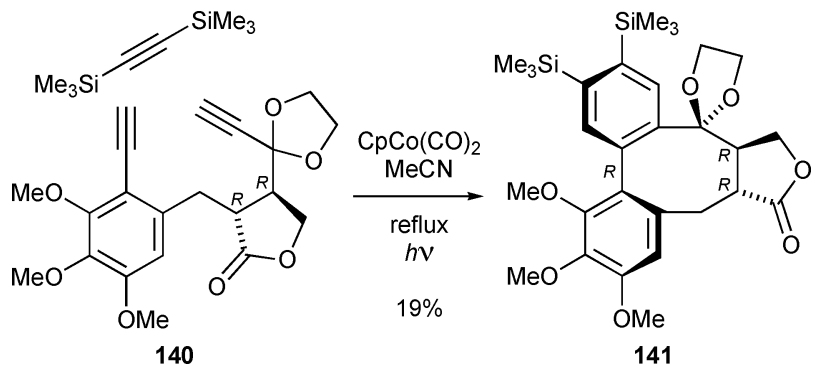

Scheme 36 A $[2+2+2]$ cycloaddition approach to (-)-steganone $34{ }^{63}$

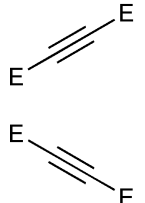<smiles>CC(=O)OCC#Cc1ccccc1Br</smiles><smiles>Cc1c(-c2ccccc2)ccc2c1CCCC2</smiles>

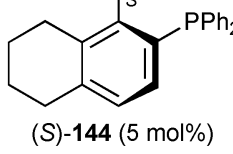

$\left[\mathrm{Rh}(\operatorname{cod})_{2}\right] \mathrm{BF}_{4}$ (5 mol\%) $\mathrm{CH}_{2} \mathrm{Cl}_{2}, \mathrm{RT}, 16 \mathrm{~h}$ $61 \%$ yield 142 (2 eq.) 143 (1 eq.) $91 \%$ e.e.<smiles>O=C(O)Cc1c(F)c(F)c(F)c(F)c1-c1ccccc1Br</smiles>

$(R)-(+)-145$

Scheme 37 Biaryl synthesis via rhodium-catalysed asymmetric cross-cyclotrimerisation. ${ }^{64}$
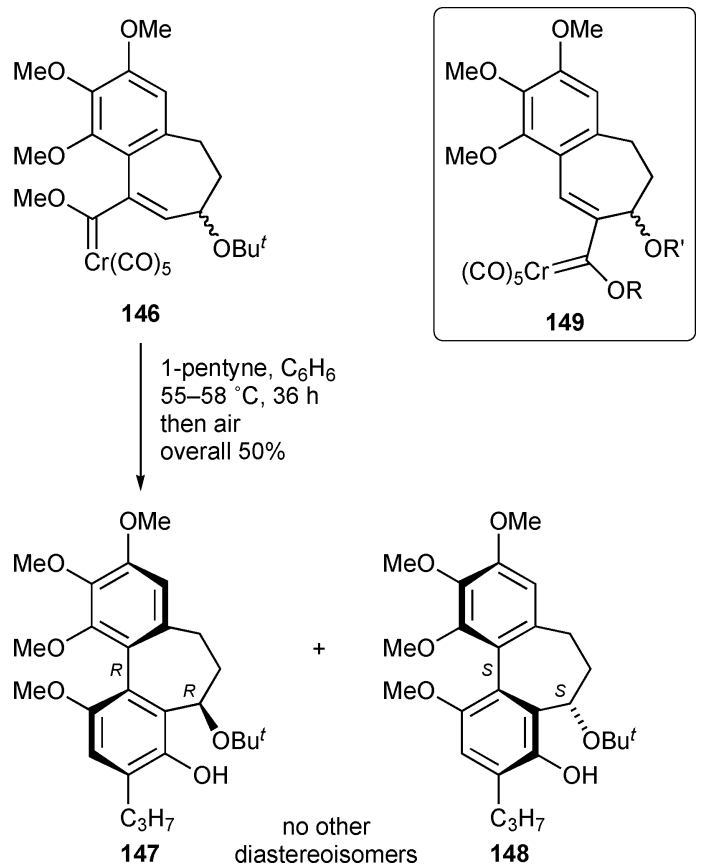

Scheme 38 Allocolchicinoids via chirality transfer benzannulation. ${ }^{65}$ 


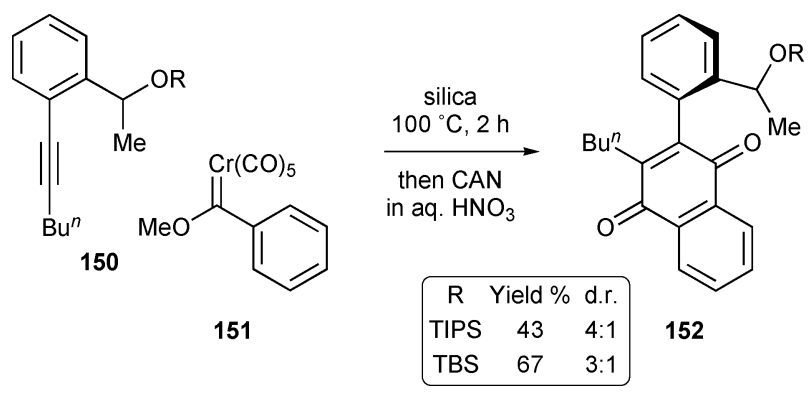

Scheme 39 Biaryl synthesis via diastereoselective benzannulation. ${ }^{66}$

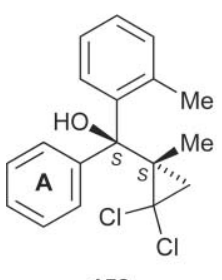

153

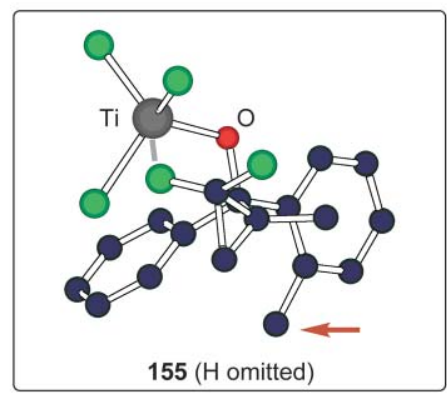

Scheme 40 Biaryl synthesis via chirality exchange benzannulation. ${ }^{67}$

An atroposelective cycloaddition approach to the nucleus of (-)-steganone 34 was devised by Motherwell and coworkers. ${ }^{63}$ The key step (Scheme 36) was the cobalt-mediated $[2+2+2]$ cycloaddition of bis(trimethylsilyl)ethyne to the tethered 1,9-diyne 140 which incorporated the necessary functionality and central chirality for elaboration to the target natural product. The product 141, obtained in 19\% yield, possessed the required $(\mathrm{a} R$ )-configured biaryl axis.

In more recent work, Tanaka and coworkers developed an asymmetric catalytic cross-cyclotrimerisation process that provides 1,1'-biaryl-2,3,4,5-tetracarboxylates with optical purities of up to $96 \%{ }^{64}$ In a typical example (Scheme 37 ), the catalyst is 0.05 equivalents of a cationic rhodium(I) species incorporating the octahydro-BINAP ligand $(S)-\mathbf{1 4 4}$.

The deployment of Fisher carbene complexes in benzannulation processes has also been modified for use as a source of axiallychiral biaryls. Efficient central-to-axial chirality transfer was observed during the construction of a series of allocolchicinoid structures, as illustrated in Scheme $38 .{ }^{65}$ The allylic stereocentre in the carbene complex 146, destined to become the benzylic stereocentre in the products 147 and 148, appears to control the axial selectivity during the annulation process, which leads to only two of the four possible diastereoisomeric products. Similar sequences using the regioisomeric starting materials 149 proceeded with similar chemical efficiency but with only moderate diastereoselectivity. In complementary study, Anderson et al. examined the effect of a stereogenic centre at the ortho (benzylic) position in the arylalkyne component of Dötz-type benzannulations. ${ }^{66}$ Reaction of the silyl ethers 150 with the carbene complex 151 followed by oxidation gave the quinones $\mathbf{1 5 2}$ with moderate diastereoselectivity that was shown to be kinetic in origin (Scheme 39). The results suggest that increasing the steric bulk of the substituent benefits atropisomer selectivity at the expense of annulation efficiency, and that the situation is finely balanced.

Another method for controlling the axial configuration of a biaryl through atroposelective aromatic ring synthesis is illustrated in Scheme 40. ${ }^{67}$ The Lewis acid-induced ionisation of 153 initiated an intramolecular cyclisation of the Friedel-Crafts type, leading to the arylnaphthalene $(\mathrm{a} R)-\mathbf{1 5 4}$ with essentially complete atroposelectivity. None of the source $\left(s p^{3}\right)$ chirality in $\mathbf{1 5 3}$ features in the product 154, making the underlying strategy one of exchange rather than transfer. The reaction is believed to involve the initial chelation of the titanium reagent to the oxygen and nearby chlorine of the cyclopropyl unit as shown in $\mathbf{1 5 5}$, with $A^{(1,3)}$ strain being minimised by the orientation of the methyl group (arrowed) away from the oxygen atom. The intermediate cation $\mathbf{1 5 6}$ develops and cyclises via this arrangement, which is stabilised by conjugation between the cyclopropylmethyl cation and the phenyl (A) ring. With other substituents in the aryl rings the reaction invariably gave a single biaryl atropisomer formed via cyclisation through the 'A' ring, as in Scheme 40, indicating that the chelation of titanium to oxygen and chlorine is a dominant feature of the mechanism.

\section{Conclusions}

The widespread interest in various theoretical, structural, synthetic and biological facets of biaryl chemistry should guarantee the status of this type of molecule, for the foreseeable future, as a primary target for the development of synthetic methodology. New methods will ideally provide access to working quantities of polyfunctional materials of any desired structure with complete control over axial configuration. Tracing the developments in this area over several years reveals that diversity has been paramount in bringing about the current state of the art and, naturally, this will continue. In an evolutionary sense, one can speculate that cross-coupling routes to chiral biaryls using chiral biaryl catalysts will prove particularly significant, bringing the possibility of autocatalysis a step closer. But only time will tell, the one certainty being that, in the expanding context of biaryl chemistry, there will be no shortage of challenges for chemists.

\section{References}

1 Reviews: (a) L. Pu, Chem. Rev., 1998, 98, 2405-2494; (b) M. McCarthy and P. J. Guiry, Tetrahedron, 2001, 57, 3809-3844; (c) R. Noyori, Angew. Chem., Int. Ed., 2002, 41, 2008-2022; (d) Y. Chen, S. Yekta and A. K. Yudin, Chem. Rev., 2003, 103, 3155-3211; (e) P. Kocovsky, S. Vyskocil and M. Smrcina, Chem. Rev., 2003, 103, 3213-3245; (f) J. M. Brunel, Chem. Rev., 2005, 105, 857-897.

2 A. Brossi, J. Med. Chem., 1990, 33, 2311-2319; Q. Shi, K. Chen, A. Brossi, P. Verdier-Pinard, E. Hamel, A. T. McPhail and K.-H. Lee, Helv. Chim. Acta, 1998, 81, 1023-1037; A. Brossi, K.-H. Lee and H. J. C. Yeh, Helv. Chim. Acta, 1999, 82, 1223-1224.

3 Heating the bisphosphate derviative of oritavancin, a semi-synthetic antibiotic related to vancomycin 4 , produces the corresponding ABatropisomer which is stable only in the solid state and reverts to 
oritavancin in solution. C. C. Zhou, E. J. Stoner, E. W. Kristensen, K. D. Stewart, R. R. Rasmussen, L. S. Hollis, S. J. Wittenberger, E. D. Matayoshi, A. C. Christesen and G. M. Brill, Tetrahedron, 2004, 60, 10611-10618.

4 For pertinent discussions, see D. A. Evans, C. J. Dinsmore, A. M. Ratz, D. A. Evrard and J. C. Barrow, J. Am. Chem. Soc., 1997, 119, 34173418; D. L. Boger, S. Miyazaki, S. H. Kim, J. H. Wu, O. Loiseleur and S. L. Castle, J. Am. Chem. Soc., 1999, 121, 3226-3227; D. L. Boger, S. Miyazaki, S. H. Kim, J. H. Wu, S. L. Castle, O. Loiseleur and Q. Jin, J. Am. Chem. Soc., 1999, 121, 10004-10011.

5 G. Bringmann, A. J. Price Mortimer, P. A. Keller, M. J. Gresser, J. Garner and M. Breuning, Angew. Chem., Int. Ed., 2005, 44, 5384-5427.

6 J. Hassan, M. Sévignon, C. Gozzi, E. Schulz and M. Lemaire, Chem. Rev., 2002, 102, 1359-1469.

7 S. Miyano, M. Tobita, S. Suzuki, Y. Nishikawa and H. Hashimoto, Chem. Lett., 1980, 1027-1030.

8 T. D. Nelson and A. I. Meyers, J. Org. Chem., 1994, 59, 2655-2658.

9 T. D. Nelson and A. I. Meyers, J. Org. Chem., 1994, 59, 2577-2580.

10 T. D. Nelson and A. I. Meyers, Tetrahedron Lett., 1994, 35, 32593262.

11 A. I. Meyers, T. D. Nelson, H. Moorlag, D. J. Rawson and A. Meier, Tetrahedron, 2004, 60, 4459-4473.

12 M. Omote, Y. Nishimura, K. Sato, A. Ando and I. Kumadaki, Tetrahedron Lett., 2005, 46, 319-322.

13 A. I. Meyers and K. A. Lutomski, J. Am. Chem. Soc., 1982, 104, 879881.

14 J. M. Wilson and D. J. Cram, J. Am. Chem. Soc., 1983, 104, 881-884; J. M. Wilson and D. J. Cram, J. Org. Chem., 1984, 49, 4930-4943.

15 A. I. Meyers, A. Meier and D. J. Rawson, Tetrahedron Lett., 1992, 33, 853-856; H. Moorlag and A. I. Meyers, Tetrahedron Lett., 1993, 34, 6989-6992.

16 A. I. Meyers, J. R. Flisak and R. A. Aitken, J. Am. Chem. Soc., 1987, 109, 5446-5452.

17 R. W. Baker, Z. Brkic, M. V. Sargent, B. W. Skelton and A. H. White, Aust. J. Chem., 2000, 53, 925-938.

18 T. Hattori, N. Koike and S. Miyano, J. Chem. Soc., Perkin Trans. 1, 1994, 2273-2282.

19 X. Li, J. Yang and M. C. Kozlowski, Org. Lett., 2001, 3, 1137-1140; X. Li, J. B. Hewgley, C. A. Mulrooney, J. Yang and M. C. Kozlowski, J. Org. Chem., 2003, 68, 5500-5511.

20 Z. Luo, Q. Liu, L. Gong, X. Cui, A. Mi and Y. Jiang, Angew. Chem., Int. Ed., 2002, 41, 4532-4535.

21 N. B. Barhate and C.-T. Chen, Org. Lett., 2002, 4, 2529-2532.

22 K. Mikami, K. Aikawa, Y. Yusa, J. J. Jodry and M. Yamanaka, Synlett, 2002, 1561-1578.

23 N. Miyaura, T. Yanagi and A. Suzuki, Synth. Commun., 1981, 11, 513519.

24 N. Miyaura and A. Suzuki, Chem. Rev., 1995, 95, 2457-2483; A. Suzuki, J. Organomet. Chem., 1999, 576, 147-168.

25 For examples and leading references, see A. F. Littke, C. Dai and G. C. Fu, J. Am. Chem. Soc., 2000, 122, 4020-4028; A. F. Littke and G. C. $\mathrm{Fu}$, Angew. Chem., Int. Ed., 2002, 41, 4176-4211; J. Yin, M. P. Rainka, X.-X. Zhang and S. L. Buchwald, J. Am. Chem. Soc., 2002, 124, 11621163; S. D. Walker, T. E. Barder, J. R. Martinelli and S. L. Buchwald, Angew. Chem., Int. Ed., 2004, 43, 1871-1876.

26 T. E. Barder, S. D. Walker, J. R. Martinelli and S. L. Buchwald, J. Am. Chem. Soc., 2005, 127, 4685-4696.

27 N. Miyaura, J. Organomet. Chem., 2002, 653, 54-57; A. A. C. Braga, N. H. Morgon, G. Ujaque and F. Maseras, J. Am. Chem. Soc., 2005, 127, 9298-9307.

28 A. L. Casado and P. Espinet, Organometallics, 1998, 17, 954-959; H. M. Senn and T. Ziegler, Organometallics, 2004, 23, 2980-2988; F. BarriosLanderos and J. F. Hartwig, J. Am. Chem. Soc., 2005, 127, 6944-6945; L. J. Goossen, D. Koley, H. L. Hermann and W. Thiel, Organometallics, 2005, 24, 2398-2410.

29 V. P. Ananikov, D. G. Musaev and K. Morokuma, J. Am. Chem. Soc., 2002, 124, 2839-2852; D. A. Culkin and J. F. Hartwig, Organometallics, 2004, 23, 3398-3416.

30 K. Osakada, H. Onodera and Y. Nishihara, Organometallics, 2005, 24, 190-192.

31 K. Kamikawa, T. Watanabe and M. Uemura, J. Org. Chem., 1996, 61, 1375-1384. For a review, see; K. Kamikawa and M. Uemura, Synlett, 2000, 938-949.

32 K. Kamikawa, T. Watanabe, A. Daimon and M. Uemura, Tetrahedron, 2000, 56, 2325-2337; T. Watanabe, Y. Tanaka, R. Shoda, R. Sakamoto,
K. Kamikawa and M. Uemura, J. Org. Chem., 2004, 69, 41524158.

33 B. H. Lipshutz and J. M. Keith, Angew. Chem., Int. Ed., 1999, 38, 3530-3533.

34 O. Baudoin, A. Décor, M. Cesario and F. Guéritte, Synlett, 2003, 20092012.

35 P.-E. Broutin and F. Colobert, Org. Lett., 2003, 5, 3281-3284; P.-E. Broutin and F. Colobert, Eur. J. Org. Chem., 2005, 1113-1128.

36 P.-E. Broutin and F. Colobert, Org. Lett., 2005, 7, 3737-3740.

37 T. Hayashi, K. Hayashizaki, T. Kiyoi and Y. Ito, J. Am. Chem. Soc., 1988, 110, 8153-8156.

38 K. C. Nicolaou, H. Li, C. N. C. Boddy, J. M. Ramanjulu, T.-Y. Yue, S. Natarajan, X.-J. Chu, S. Bräse and F. Rübsam, Chem.-Eur. J., 1999, 5, 2584-2601.

39 (a) G. Bringmann, A. Hamm and M. Schraut, Org. Lett., 2003, 5, 2805-2808. Table 1 in this paper contains typing errors with respect to the equivalents of catalyst $\mathbf{8 9}$ used; $(b)$ G. Bringmann, R.-M. Pfeifer, P. Schreiber, K. Hartner, M. Schraut and M. Breuning, Tetrahedron, 2004, 60, 4349-4360.

40 A.-S. Castanet, F. Colobert, P.-E. Broutin and M. Obringer, Tetrahedron: Asymmetry, 2002, 13, 659-665.

41 A. N. Cammidge and K. V. L. Crépy, Chem. Commun., 2000, 17231724 (erratum: A. N. Cammidge and K. V. L. Crépy, Chem. Commun., 2001, 389); A. N. Cammidge and K. V. L. Crépy, Tetrahedron, 2004, 60, 4377-4386.

42 J. Yin and S. L. Buchwald, J. Am. Chem. Soc., 2000, 122, 12051-12052.

43 J. F. Jensen and M. Johannsen, Org. Lett., 2003, 5, 3025-3028.

44 K. Mikami, T. Miyamoto and M. Hatano, Chem. Commun., 2004, 2082-2083.

45 A. Herrbach, A. Marinetti, O. Baudoin, D. Guénard and F. Guéritte, J. Org. Chem., 2003, 68, 4897-4905.

46 P. Kocovsky, S. Vyskocil, I. Cisarova, J. Sejbal, I. Tislerova, M. Smrcina, G. C. Lloyd-Jones, S. C. Stephen, C. P. Butts, M. Murray and V. Langer, J. Am. Chem. Soc., 1999, 121, 7714-7715.

47 D. A. Evans and C. J. Dinsmore, Tetrahedron Lett., 1993, 34, 6029 6032. See also; D. A. Evans, C. J. Dinsmore, D. A. Evrard and K. M. DeVries, J. Am. Chem. Soc., 1993, 115, 6426-6427.

48 B. H. Lipshutz, P. Müller and D. Leinweber, Tetrahedron Lett., 1999, 40, 3677-3680.

49 L. A. Saudan, G. Bernardinelli and E. P. Kündig, Synlett, 2000, 483486.

50 G. Michaud, M. Bulliard, L. Ricard, J.-P. Genêt and A. Marinetti, Chem.-Eur. J., 2002, 8, 3327-3330.

51 D. R. Spring, S. Krishnan, H. E. Blackwell and S. L. Schreiber, J. Am. Chem. Soc., 2002, 124, 1354-1363.

52 S. Krishnan and S. L. Schreiber, Org. Lett., 2004, 6, 4021-4024.

53 B. H. Lipshutz, D. J. Buzard, C. Olsson and K. Noson, Tetrahedron, 2004, 60, 4443-4449.

54 G. Bringmann, J. Hinrichs, T. Pabst, P. Henschel, K. Peters and E.-M. Peters, Synthesis, 2001, 155-167; G. Bringmann and D. Menche, Acc. Chem. Res., 2001, 34, 615-624.

55 G. Bringmann and T. Hartung, Tetrahedron, 1993, 49, 7891-7902.

56 G. Bringmann, D. Menche, J. Mühlbacher, M. Reichert, N. Saito, S. S. Pfeiffer and B. H. Lipshutz, Org. Lett., 2002, 4, 2833-2836.

57 Y.-H. Cho, A. Kina, T. Shimada and T. Hayashi, J. Org. Chem., 2004, 69, 3811-3823.

58 T. M. T. Tuyet, T. Harada, K. Hashimoto, M. Hatsuda and A. Oku, J. Org. Chem., 2000, 65, 1335-1343.

59 D. J. Edwards, R. G. Pritchard and T. W. Wallace, Tetrahedron Lett., 2003, 44, 4665-4668.

60 M. Penhoat, V. Levacher and G. Dupas, J. Org. Chem., 2003, 68, $9517-$ 9520.

61 D. J. Edwards, S. J. Stone and T. W. Wallace, unpublished results.

62 M. Penhoat, S. Leleu, G. Dupas, C. Papamicaël, F. Marsais and V. Levacher, Tetrahedron Lett., 2005, 46, 8385-8389.

63 A. Bradley, W. B. Motherwell and F. Ujjainwalla, Chem. Commun., 1999, 917-918.

64 K. Tanaka, G. Nishida, M. Ogino, M. Hirano and K. Noguchi, Org. Lett., 2005, 7, 3119-3121.

65 A. V. Vorogushin, W. D. Wulff and H.-J. Hansen, J. Am. Chem. Soc., $2002, \mathbf{1 2 4}, 6512-6513$.

66 J. C. Anderson, J. W. Cran and N. P. King, Tetrahedron Lett., 2003, 44, 7771-7774.

67 Y. Nishii, K. Wakasugi, K. Koga and Y. Tanabe, J. Am. Chem. Soc., 2004, 126, 5358-5359. 